\title{
新型异长叶烷基二氢嘧啶硫酮类衍生物的合成及其抗肿瘤活性研究
}

\author{
马崇慧 ${ }^{a}$ 吴陈亮 ${ }^{a} \quad$ 王芸芸 ${ }^{a} \quad$ 黄真真 $^{b} \quad$ 张强健 $^{a}$

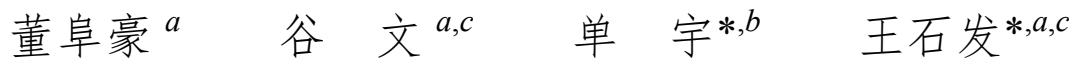 \\ ( ${ }^{a}$ 南京林业大学化学工程学院 南京 210037) \\ ( ${ }^{b}$ 江苏省中国科学院植物研究所 南京 210014) \\ ( ${ }^{c}$ 南京林业大学林业资源高效加工利用协同创新中心 南京 210037)
}

\begin{abstract}
摘要 以异长叶烷酮为起始物, 经羟醛缩合、环化等手段, 合成了 12 种异长叶烷基二氢嘧啶硫酮类衍生物, 通过 ${ }^{1} \mathrm{H}$ $\mathrm{NMR} 、{ }^{13} \mathrm{C}$ NMR 及高分辨质谱(HRMS)对其结构进行了表征，通过 $\mathrm{X}$ 射线衍射分析测定了化合物 $3 \mathbf{e}$ 的晶体结构. 探索 了这些衍生物对人乳腺癌细胞(MDA-MB-231)、人宫颈癌细胞(HeLa)、人肝癌细胞(HepG-2)等三种癌细胞和一种正常 细胞即小鼠巨噬细胞(RAW-264.7)的体外抗增殖活性. 结果表明, 这 12 种化合物显示出较好的抗肿㿔活性, 其 $\mathrm{IC}_{50}$ 值在 $3.12 \sim 44.28 \mu \mathrm{mol} / \mathrm{L}$ 范围内. 其中, 化合物 $3 \mathbf{j}$ 对 MDA-MB- 231 细胞表现出最强的抗肿瘤活性 $\left(\mathrm{IC}_{50}=3.12 \mu \mathrm{mol} / \mathrm{L}\right)$, 化合 物 $3 \mathrm{~g}$ 对 $\mathrm{HeLa}$ 细胞表现出最强的抗肿瘤活性 $\left(\mathrm{IC}_{50}=4.04 \mu \mathrm{mol} / \mathrm{L}\right)$, 化合物 $3 \mathrm{k}$ 对 HepG-2 细胞表现出最强的抗肿瘤活性 $\left(\mathrm{IC}_{50}=5.43 \mu \mathrm{mol} / \mathrm{L}\right)$. 此外, 化合物 $\mathbf{3 j}$ 将 MDA-MB-231 细胞阻滞在 $\mathrm{G} 0 / \mathrm{G} 1$ 期, 并以剂量依赖的方式诱导 MDA-MB-231 细胞的早期凋亡.
\end{abstract}

关键词 异长叶烷酮; 二氢嘧啶硫酮类衍生物; 抗肿瘤活性

\section{Synthesis and Antitumor Activity of Novel Isolongifolic-Alkyl Dihydropyrimidinethione Derivatives}

\author{
Ma, Chonghui ${ }^{a} \quad \mathrm{Wu}$, Chenliang $^{a} \quad$ Wang, Yunyun $^{a} \quad$ Huang, Zhenzhen ${ }^{b}$ \\ Zhang, Qiangjian $^{a} \quad$ Dong, Fuhao $^{a} \quad \mathrm{Gu}, \mathrm{Wen}^{a, c} \quad$ Shan, Yu${ }^{*, b}$ Wang, Shifa ${ }^{*, a, c}$ \\ ( ${ }^{a}$ College of Chemical Engineering, Nanjing Forestry University, Nanjing 210037) \\ ( ${ }^{b}$ Jiangsu Key Laboratory for the Research and Utilization of Plant Resources, Institute of Botany, Jiangsu Province and \\ Chinese Academy of Sciences, Nanjing 210014) \\ ( ${ }^{c}$ Co-Innovation Center of Efficient Processing and Utilization of Forest Resources, \\ Nanjing Forestry University, Nanjing 210037)
}

\begin{abstract}
In this work, twelve dihydropyrimidinethione derivatives have been synthesized from isolongifolanone by aldol and cyclization reactions. The chemical structures were characterized by ${ }^{1} \mathrm{H} N M R,{ }^{13} \mathrm{C}$ NMR and high resolution mass spectrometry (HRMS), and the structure of compound 3e was determined by X-ray single crystal diffraction. Their in vitro cytotoxicity against three cancer cell lines breast (MDA-MB-231), cervix (HeLa), liver (HepG-2) and one normal cell line mouse macrophages (Raw-264.7) were investigated. It was shown that these 12 compounds had good antitumor activity with $\mathrm{IC}_{50}$ values of 3.12 44.28 $\mu \mathrm{mol} / \mathrm{L}$. Among them, compounds $\mathbf{3 j}, \mathbf{3 g}$, and $\mathbf{3 k}$ had the best antitumor activity against MDA-MB-231 cells $\left(\mathrm{IC}_{50}=3.12 \mu \mathrm{mol} / \mathrm{L}\right), \mathrm{HeLa}$ cells $\left(\mathrm{IC}_{50}=4.04 \mu \mathrm{mol} / \mathrm{L}\right)$ and HepG-2 cells $\left(\mathrm{IC}_{50}=5.43 \mu \mathrm{mol} / \mathrm{L}\right)$, respectively. In addition, compound $3 \mathbf{j}$ arrested the cells in the G0/G1 phase of the MDA-MB-231 cell cycle and induced the early apoptosis of MDA-MB-231 cells in a dose-dependent manner.

Keywords isolongifolanone; dihydropyrimidinethione derivatives; antitumor activity
\end{abstract}

* Corresponding authors. E-mail: attilayu@hotmail.com; wangshifa65@163.com

Received July 11, 2018; revised September 24, 2018; published online October 19, 2018.

Project supported by the National Natural Science Foundation of China (No. 31470592).

国家自然科学基金(No. 31470592)资助项目. 


\section{Introduction}

Cancer is considered as a major health problem worldwide because of the high rate of mortality. In 2012 alone, 14 million cancer cases and 8.2 million cancer-related deaths have occurred. ${ }^{[1]}$ Moreover, cancer cases is expected to rise to almost 20 million by $2025 .{ }^{[2]}$ Cancer characterized by uncontrolled and abnormal growth of cells, which is considered as the second cause of mortality after cardiovascular diseases. Therefore, it remains important to screening for new anticancer agents and which is one of the major goals in medicinal chemistry.

Pyrimidines, an important component of nucleic acids, have been used as framework in pharmaceuticals for the synthesis of antineoplastic, ${ }^{[3]}$ antiviral, ${ }^{[4]}$ antibacterial and antifungal agents. ${ }^{[5]}$ Thiouracils are a vital class of revised nucleobases derived from uracil, and their derivatives are potential therapeutical agents with anticancer, antiviral, and microbial activities. ${ }^{[6 \sim 8]}$ For example, 6-methyl-2thiouracil, a typical thiouracil derivative which has good biological and antifungal activities. It is an active pharmaceutical ingredient which containing active (HN-CS-NH) and pyrimidine heterocyclic group. ${ }^{[9 \sim 16]}$ In addition, thiouracils and their derivatives are used as hyperthyroidism inhibitors. The inhibitors which induce emendations in the thyroid. Scilicet, when they exist in blood or dietary products, thiouracils and their derivatives will impair thyroid activity. $^{[17]}$

Turpentine is an abundant renewable resource, and the main components of turpentine are $\alpha$-pinene, $\beta$-pinene and longifolene. Isolongifolene is a tricyclic sesquiterpene which can be obtained from longifolene by isomerization reaction. ${ }^{[18,19]}$ Isolongifolene is oxidized to generate isolongifolanone, which is also extensively used in pharmaceutical and perfumery industries due to its woody amber odor. ${ }^{[20,21]}$ Isolongifolanone can convert to other derivatives which have amazing applications as bactericidal and antibacterial, ${ }^{[22]}$ anti-tumor, ${ }^{[22,23]}$ anti-tuberculosis, ${ }^{[22]}$ anti-cancer ${ }^{[22,24]}$ anti-inflammatory, ${ }^{[22]}$ analgesic, ${ }^{[22]}$ anti-depressant, ${ }^{[22]}$ anti-diabetic ${ }^{[22]}$ and antimicrobial. ${ }^{[24,25]}$

In the past several years, our laboratory has been conducting many researches on the applications of isolongifolanone, such as anti-inflammatory, ${ }^{[26]}$ anticancer, ${ }^{[26]}$ and fluorescent dyes. ${ }^{[27,28]}$ However, the synthesis of isolongifolanone-based dihydropyrimidinethione derivatives have been reported in few literatures. The above discoveries offer us a direction to design and synthesize dihydropyrimidinethione derivatives of isolongifolanone and probe into their possible values as anticancer drugs.

\section{Results and discussion}

\subsection{Chemistry}

The synthesis of designed dihydropyrimidinethione derivatives were outlined in Scheme 1. Compounds $2 \mathbf{2 a} \sim 2 \mathbf{2}$ were prepared according to our previously reported methods. ${ }^{[27,29]}$ Compounds $\mathbf{2 a} \sim \mathbf{2 l}$ were converted into com-

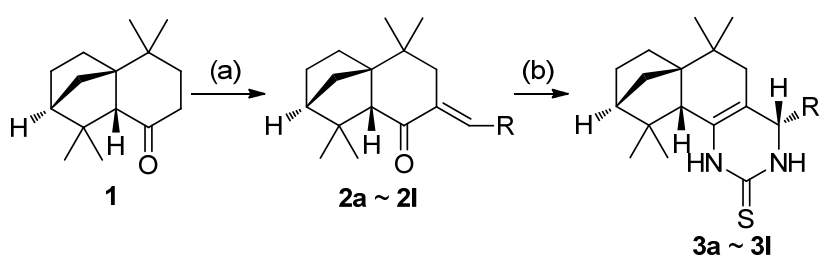

R: 4-chlorophenyl (a); 4-bromophenyl(b); 4-fluorophenyl (c); 4-methylphenyl (d); 4-methoxyphenyl (e); phenyl (f); 2-pyridyl (g); 2-chlorophenyl (h); 2-bromophenyl (i); 2-fluorophenyl (j); 2-methylphenyl (k); 2-methoxyphenyl (I)

Reagents and conditions: (a) substituted benzaldehyde, potassium tert-butoxide, tert-butanol/ethanol, reflux, $4 \sim 12 \mathrm{~h}$; (b) thiourea, potassium tert-butoxide, tert-butanol and ethanol, reflux, $30 \mathrm{~h}$

Scheme 1 Synthesis of compounds $\mathbf{3 a} \sim \mathbf{3 I}$

pounds $\mathbf{3 a} \sim \mathbf{3 l}$ by reacting with thiourea using potassium tert-butoxide in ethanol and tert-butyl alcohol. The target compounds $\mathbf{3 a} \sim \mathbf{3} \mathbf{I}$ were characterized by NMR and HRMS. Moreover, compound 3e was determined by single-crystal X-ray diffraction (Table 1, Figure 1).

Table 1 Crystal data, diffraction data, and refinement data of compound 3e

\begin{tabular}{|c|c|}
\hline Moiety formula & $\mathrm{CHCl}_{3}, \mathrm{C}_{24} \mathrm{H}_{32} \mathrm{~N}_{2} \mathrm{OS}$ \\
\hline$M_{\mathrm{r}}$ & 515.94 \\
\hline Bond precision $/ \AA$ & $\mathrm{C}-\mathrm{C} 0.0063$ \\
\hline Wavelength/Å & 0.71076 \\
\hline$a / \AA$ & $13.3915(8)$ \\
\hline$b / \AA$ & $8.8877(5)$ \\
\hline$c / \AA$ & $22.5152(14)$ \\
\hline$\alpha /\left(^{\circ}\right)$ & 90 \\
\hline$\beta /\left({ }^{\circ}\right)$ & $105.765(2)$ \\
\hline$\gamma /\left(^{\circ}\right)$ & 90 \\
\hline$T / \mathrm{K}$ & 283 \\
\hline Volume & $2578.9(3)$ \\
\hline Space group & $P 121 / n 1$ \\
\hline Hall group & $-P 2 y n$ \\
\hline$Z$ & 4 \\
\hline$M_{\mathrm{u}} / \mathrm{m}^{-1}$ & 0.457 \\
\hline$D_{\mathrm{x}} /\left(\mathrm{g} \cdot \mathrm{cm}^{-3}\right)$ & 1.329 \\
\hline$F(000)$ & 1088.0 \\
\hline$h, k, l(\max )$ & $15,10,26$ \\
\hline$N_{\text {ref }}$ & 4551 \\
\hline$T_{\min }, T_{\max }$ & $0.656,0.746$ \\
\hline Data completeness & 0.999 \\
\hline$\theta(\max )$ & 25.000 \\
\hline$R$ (reflections) & $0.0749(2848)$ \\
\hline$w R_{2}$ & $0.1975(4551)$ \\
\hline$S$ & 1.021 \\
\hline Npar & 294 \\
\hline
\end{tabular}

\subsection{Biological evaluation}

The biological activities of compounds $\mathbf{3 a} \sim \mathbf{3 1}$ in inhibiting cancer cell index proliferation were assayed against MDA-MB-231 cell line, HeLa cell line, HepG-2 cell line and normal cell line Raw-264.7 (mouse macrophages) using in vitro $\mathrm{MTT}$ assay. The $\mathrm{IC}_{50}(\mu \mathrm{mol} / \mathrm{L})$ values of 


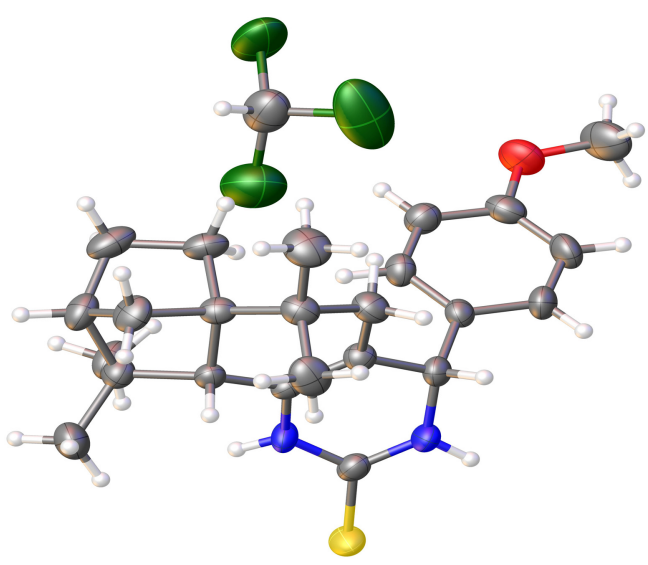

Figure 1 X-ray crystal structure of compound $3 \mathrm{e}$.

compounds $\mathbf{3 a} \sim \mathbf{3 1}$ and reference standard of etoposide $\mathrm{e}^{[30]}$ have been listed in Table 2 .

The antitumor activities of compounds $\mathbf{3 b}, \mathbf{3 c}, \mathbf{3} \mathbf{f}$ and $\mathbf{3 j}$ against MDA-MB-231 cells were better than the antitumor activity of the positive drug etoposide $\left(\mathrm{IC}_{50}=8.66 \mu \mathrm{mol} /\right.$ L). Among them, compound $3 \mathbf{j}$ showed the best anti-proliferative activity on MDA-MB-231 cells with an $\mathrm{IC}_{50}$ value of $3.12 \mu \mathrm{mol} / \mathrm{L}$. In addition, compound $\mathbf{3 g}$ exhibited the strongest antiproliferative activity on HeLa cells $\left(\mathrm{IC}_{50}=4.04 \mu \mathrm{mol} / \mathrm{L}\right)$. Most of the target compounds $(\mathbf{3 a} \sim 3 \mathbf{c}, 3 \mathbf{e}, \mathbf{3 f}, \mathbf{3 h}, \mathbf{3 j} \sim \mathbf{3 l})$ showed good biological activity against HepG-2 cells $\left(\mathrm{IC}_{50}<10 \mu \mathrm{mol} / \mathrm{L}\right)$, and compound 3k showed the best antiproliferative activity on HepG-2 cells $\left(\mathrm{IC}_{50}=5.43 \mu \mathrm{mol} / \mathrm{L}\right)$. It was worth noting that this class of compounds with para-substituents had no obvious cytotoxicity effect on normal cell mouse macrophages (RAW-264.7) with $\mathrm{IC}_{50}>50 \mu \mathrm{mol} / \mathrm{L}$.

It was known from the results of in vitro antitumor activity tests that when the ortho- or para-position of the $\mathrm{R}$ group contained $\mathrm{Cl}, \mathrm{Br}, \mathrm{F}, \mathrm{NO}_{2}$ etc. electron-withdrawing groups, compounds $\mathbf{3 a} \sim \mathbf{3} \mathbf{c}$ and $\mathbf{3 h} \sim \mathbf{3} \mathbf{j}$ had better inhibitory activity against MDA-MB-231 cells than compounds 3d, 3e, 3k, 31 which had electron-donating groups $\left(\mathrm{CH}_{3}\right.$, $\mathrm{OCH}_{3}$ ). Whereas, the compounds showed better antitumor activities against MDA-MB-231 cells when the substituents in ortho-position $(\mathbf{3 h}, \mathbf{3} \mathbf{j}, \mathbf{3 k}, \mathbf{3} \mathbf{)})$. Interestingly, compounds $\mathbf{3 b}$ and $\mathbf{3 i}$ did not follow the rule. It could be found that compounds $3 \mathbf{a}, \mathbf{3 c}$ with electron-withdrawing groups in para-position were conferred better antitumor activities against HeLa cells than compounds 3d, 3e with electron-donating groups in para-position. Compounds $\mathbf{3 h}, \mathbf{3} \mathbf{j}$ with electron-withdraw- ing groups in ortho-position have greatly reduced the activity against HeLa cells compared with compounds $3 \mathbf{k}, 3 \mathbf{3}$ bearing electron-donating groups in ortho-position. When the compounds have the same electron-withdrawing groups $(\mathrm{Cl}, \mathrm{F})$, compounds $\mathbf{3 a}, \mathbf{3 c}$ whose substituents in para-position have better anti-proliferative activity against HeLa cells than compounds $\mathbf{3 h}, \mathbf{3 j}$ with substituents in ortho-position. The target compounds have generally good anti-proliferative activities against HepG-2 cells.

To probe whether cell apoptosis of MDA-MB-231 cells induced by compound $\mathbf{3} \mathbf{j}$, the cell apoptosis was evaluated by flow cytometric analysis. As illustrated in Figure 2, compound $\mathbf{3} \mathbf{j}$ caused cell apoptosis in a dose-dependent manner. The cells in the control group were in good condition, normal cells accounted for $90.8 \%$. After treatment with different doses of compound $\mathbf{3 j}(0,2,5,10 \mu \mathrm{mol} / \mathrm{L})$, the percentage of early apoptotic cells increased from $8.50 \%$ to $42.3 \%$ significantly. These results explored that compound $\mathbf{3 j}$ might induce dose-dependent apoptosis of MDA-MB-231 cells efficiently.

To investigate whether the antitumor effects on MDAMB-231 cells growth of compound $\mathbf{3 j}$ was caused by cell cycle arrest, MDA-MB-231 cells was treated with different doses of compound $\mathbf{3} \mathbf{j}$. The percentage of cells in each cell cycle phase was evaluated by flow cytometry (Figure 3). In the control group, cell populations in the $\mathrm{G} 0 / \mathrm{G} 1, \mathrm{~S}$ and $\mathrm{G} 2 / \mathrm{M}$ phases were $55.71 \%, 26.51 \%$ and $16.77 \% .5 \mu \mathrm{mol} / \mathrm{L}$ of compound $\mathbf{3} \mathbf{j}$ reduced the percentage of MDA-MB-231 cells at the G2/M phase and induced an accumulation of MDA-MB-231 cells in G0/G1 phase. The percentage of cells in $\mathrm{G} 2 / \mathrm{M}$ phase decreased to $8.72 \%$, while the G0/G1

Table 2 The anticancer activity and cytotoxicity of compounds $\mathbf{3 a} \sim \mathbf{3 1}$

\begin{tabular}{|c|c|c|c|c|c|}
\hline \multirow{2}{*}{ Compound } & \multirow{2}{*}{$\mathrm{R}$} & \multicolumn{4}{|c|}{$\mathrm{IC}_{50}\left(\mu \mathrm{mol} \cdot \mathrm{L}^{-1}\right)$} \\
\hline & & MBA-MD-231 & $\mathrm{HeLa}$ & HepG-2 & Raw264.7 \\
\hline $3 a$ & $4-\mathrm{ClC}_{6} \mathrm{H}_{4}$ & $11.65 \pm 0.09$ & $8.85 \pm 0.03$ & $8.92 \pm 0.12$ & $>50$ \\
\hline $3 \mathbf{b}$ & $4-\mathrm{BrC}_{6} \mathrm{H}_{4}$ & $5.13 \pm 0.12$ & $16.23 \pm 0.03$ & $8.89 \pm 0.04$ & $>50$ \\
\hline $3 c$ & $4-\mathrm{FC}_{6} \mathrm{H}_{4}$ & $7.00 \pm 0.06$ & $7.40 \pm 0.03$ & $8.52 \pm 0.08$ & $>50$ \\
\hline 3d & 4- $\mathrm{CH}_{3} \mathrm{C}_{6} \mathrm{H}_{4}$ & $25.01 \pm 0.03$ & $10.74 \pm 0.01$ & $11.99 \pm 0.07$ & $>50$ \\
\hline $3 e$ & $4-\mathrm{CH}_{3} \mathrm{OC}_{6} \mathrm{H}_{4}$ & $25.73 \pm 0.09$ & $15.86 \pm 0.01$ & $6.48 \pm 0.07$ & $>50$ \\
\hline $3 f$ & $\mathrm{C}_{6} \mathrm{H}_{5}$ & $6.94 \pm 0.06$ & $7.09 \pm 0.05$ & $8.17 \pm 0.02$ & $32.94 \pm 0.15$ \\
\hline $3 g$ & $2-\mathrm{NC}_{5} \mathrm{H}_{4}$ & $44.28 \pm 0.02$ & $4.04 \pm 0.14$ & $14.94 \pm 0.04$ & $>50$ \\
\hline $3 h$ & $2-\mathrm{ClC}_{6} \mathrm{H}_{4}$ & $9.02 \pm 0.17$ & $22.40 \pm 0.54$ & $6.35 \pm 0.12$ & $13.94 \pm 0.16$ \\
\hline $3 \mathbf{i}$ & $2-\mathrm{BrC}_{6} \mathrm{H}_{4}$ & $9.56 \pm 0.21$ & $9.62 \pm 0.06$ & $10.16 \pm 0.07$ & $15.08 \pm 0.24$ \\
\hline $3 \mathbf{j}$ & $2-\mathrm{FC}_{6} \mathrm{H}_{4}$ & $3.12 \pm 0.26$ & $30.34 \pm 0.06$ & $8.79 \pm 0.05$ & $6.97 \pm 0.16$ \\
\hline $3 \mathbf{k}$ & $2-\mathrm{CH}_{3} \mathrm{C}_{6} \mathrm{H}_{4}$ & $16.62 \pm 0.09$ & $9.20 \pm 0.03$ & $5.43 \pm 0.08$ & ND \\
\hline 31 & 2- $\mathrm{CH}_{3} \mathrm{OC}_{6} \mathrm{H}_{4}$ & $18.27 \pm 0.10$ & $12.21 \pm 0.06$ & $7.922 \pm 0.10$ & ND \\
\hline Etoposide & & $8.66 \pm 0.03$ & $5.48 \pm 0.04$ & $2.444 \pm 0.09$ & $10.74 \pm 0.03$ \\
\hline
\end{tabular}




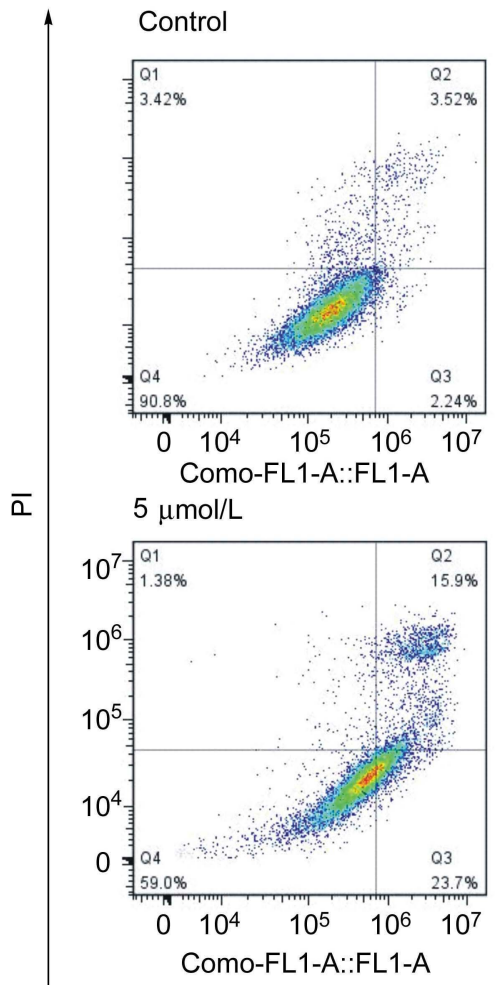

$2 \mu \mathrm{mol} / \mathrm{L}$

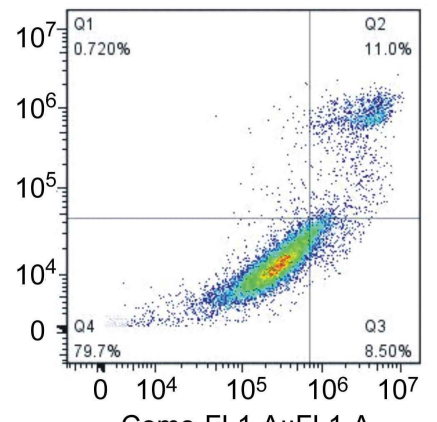

$10 \mu \mathrm{mol} / \mathrm{L}$

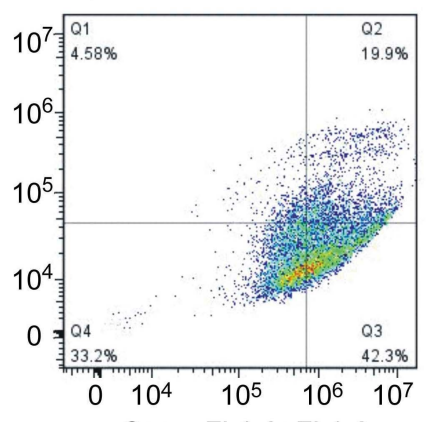

Como-FL1-A::FL1-A

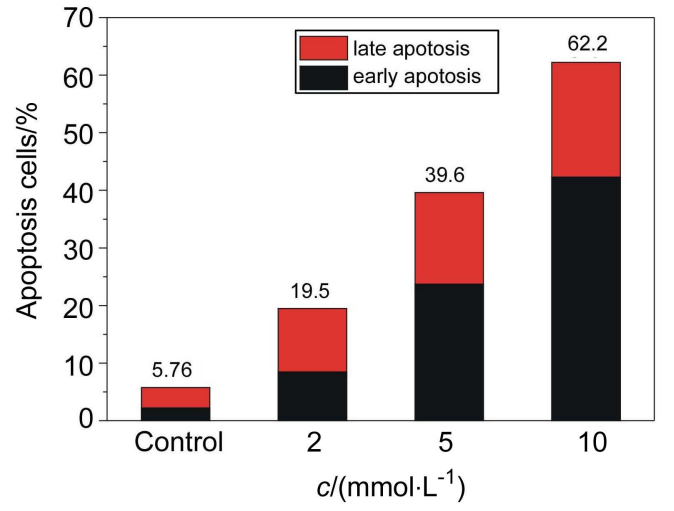

Figure 2 Effects of compound $\mathbf{3 j}$ on the apoptosis of MDA-MB-231 cells
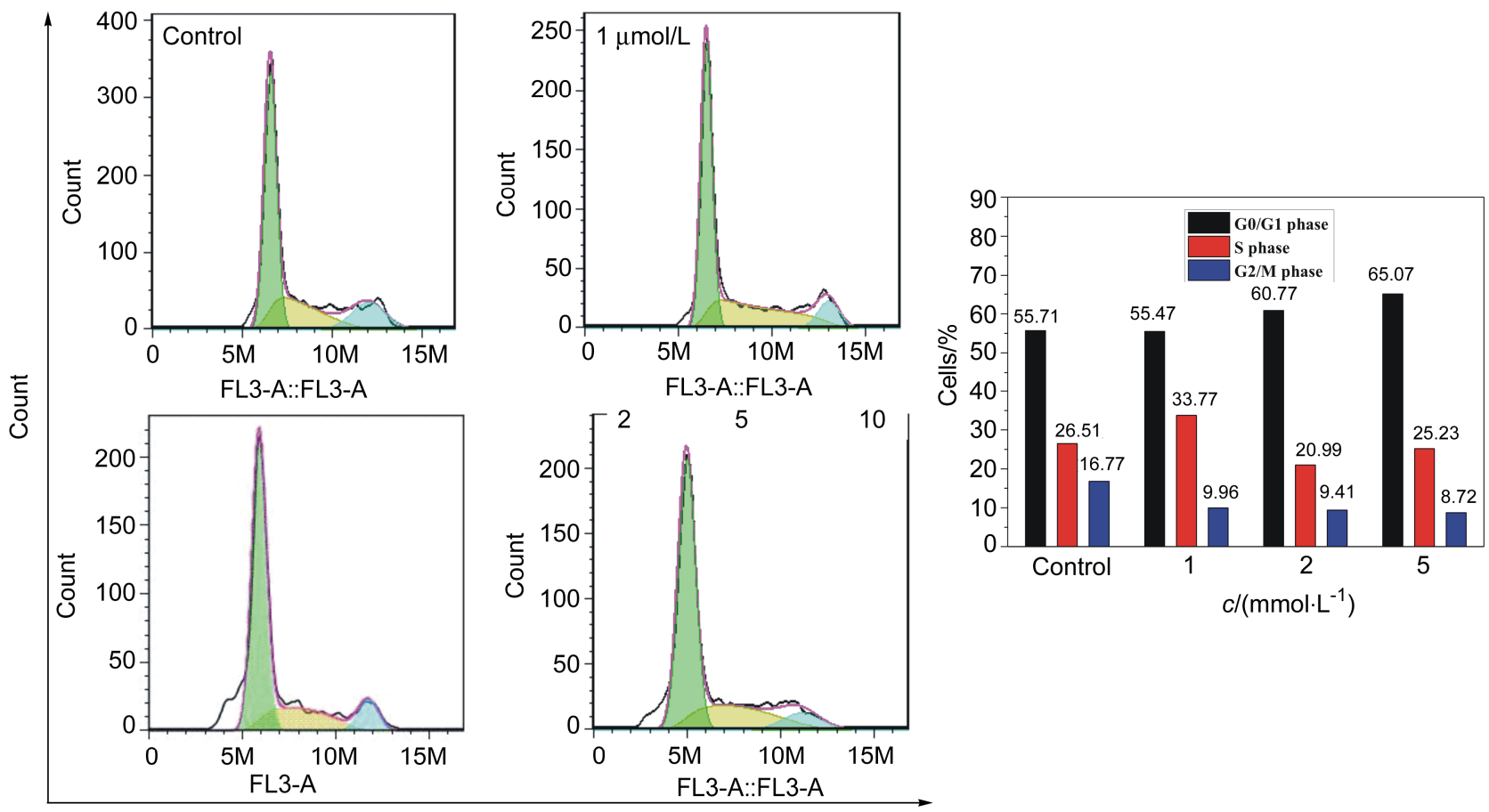

Figure 3 Effects of compound $\mathbf{3} \mathbf{j}$ on the MDA-MB-231 cells cycle

phase cells increased to $65.07 \%$. Those phenomena in the cell cycle distribution on $\mathbf{3} \mathbf{j}$ treatment indicated that it induced cell cycle arrest at the G0/G1 phase.

\section{Conclusions}

12 new isolongifolanone-based dihydropyrimidinethione derivatives $\mathbf{3 a} \sim 31$ have been synthesized, and their bio- 
logical activity in inhibiting cancer cell proliferation were evaluated. The compounds in large part showed favorable growth inhibitory activity against three cancer cell lines breast (MDA-MB-231), cervix (HeLa) and liver (HepG-2). It was found that compound $\mathbf{3} \mathbf{j}$ showed potent cytotoxicity on MDA-MB-231 cells $\left(\mathrm{IC}_{50}=3.12 \mu \mathrm{mol} /\right.$ ), compound $\mathbf{3 g}$ exhibited best antitumor activity against HeLa cells $\left(\mathrm{IC}_{50}=4.04 \mu \mathrm{mol} / \mathrm{L}\right)$, while compound $3 \mathbf{k}$ showed most potent cytotoxicity on HepG-2 cells $\left(\mathrm{IC}_{50}=5.43 \mu \mathrm{mol} /\right)$. In addition, compound $\mathbf{3 j}$ arrested the cells in the G0/G1 phase of the MDA-MB-231 cell cycle and induced the apoptosis of MDA-MB-231 cells. The above discoveries emphasized the potential of the series of derivatives as new antitumor drugs. More study will be proceeded to explore the in-depth structure-activity relationships and the anticancer mechanisms.

\section{Experimental}

\subsection{Instruments}

The reactions were monitored by chromatography and observed under a UV lamp at a wavelength of $254 \mathrm{~nm}$. UV-visible absorption spectra were investigated by PerkinElmer Lambda 950. ${ }^{1} \mathrm{H} \mathrm{NMR}\left(400 \mathrm{MHz}, \mathrm{CDCl}_{3}\right)$ and ${ }^{13} \mathrm{C}$ NMR $\left(100 \mathrm{MHz}, \mathrm{CDCl}_{3}\right)$ spectra were recorded in $\mathrm{CDCl}_{3}$ on a Bruker AV $400 \mathrm{MHz}$ Spectrometer. Purities were measured on an America Agilent 1260 Liquid Chromatography (The type of column was $\mathrm{C} 18$ and the ratio of water to acetonitrile in the mobile phase was 95:5). High-resolution mass data were obtained on QSTAR Elite High-resolution liquid tandem mass spectrometer. Single-crystal X-ray diffraction measurements were done on a Bruker D8 Venture Area Diffractometer. Melting points were performed with X-6 Micro Melting Point Detector from Beijing Tektronix. The cell apoptosis and cell cycle were evaluated by Flow Cytometer (C6).

\subsection{Materials}

Unless otherwise stated, all the reagents and solvents were purchased from commercial suppliers without further purification. Isolongifolanone was purchased from Jianyang Flavor Company, purity 80\%. Cells: Human breast cancer MDA-MB-231 cells, human cervical cancer Hela cells, Human hepatoma HepG-2 cells and mouse macrophages RAW-264.7 were provided by Chinese Academy of Sciences Cell Bank.

\subsection{Synthesis}

\subsubsection{Synthesis of compounds $\mathbf{2 a} \sim \mathbf{2 l}$}

To a solution of isolongifolanone $(0.05 \mathrm{~mol})$ in ethanol $(120 \mathrm{~mL})$ was added substituted benzaldehyde $(0.065 \mathrm{~mol})$ and potassium tert-butoxide $(5 \mathrm{mmol})$, then the reaction mixture was stirred for $4 \sim 24 \mathrm{~h}$ at reflux temperature. When the reaction was completed (monitored by TLC), the reaction solvent was removed off, and $50 \mathrm{~mL}$ saturated brine was added into the mixture, and then extracted three times with ethyl acetate $(50 \mathrm{~mL} \times 3)$, the organic layers were washed to neutrality, dried by $\mathrm{Na}_{2} \mathrm{SO}_{4}$, filtered and concentrated under reduced pressure. The resulted residues were then purified by recrystallization from methanol to afford $\mathbf{2 a} \sim \mathbf{2 l}$.

7-(4'-Chlorobenzylidene)-isolongifolanone (2a): Yellow crystal, yield 93.5\%. m.p. $159.1 \sim 159.9{ }^{\circ} \mathrm{C} \quad$ (lit. $^{[26]}$ $\left.158.4 \sim 159.1{ }^{\circ} \mathrm{C}\right) ;{ }^{1} \mathrm{H}$ NMR $\left(600 \mathrm{MHz}, \mathrm{CDCl}_{3}\right) \delta: 0.85(\mathrm{~s}$, $3 \mathrm{H}), 0.87(\mathrm{~s}, 3 \mathrm{H}), 1.06(\mathrm{~s}, 3 \mathrm{H}), 1.08 \sim 1.13(\mathrm{~m}, 1 \mathrm{H}), 1.24$ $(\mathrm{s}, 3 \mathrm{H}), 1.31 \sim 1.32(\mathrm{~m}, 1 \mathrm{H}), 1.49 \sim 1.55(\mathrm{~m}, 1 \mathrm{H}), 1.63 \sim$ $1.68(\mathrm{~m}, 1 \mathrm{H}), 1.78 \sim 1.81(\mathrm{~m}, 2 \mathrm{H}), 1.83 \sim 1.87(\mathrm{~m}, 1 \mathrm{H})$, $1.99(\mathrm{~d}, J=2.0 \mathrm{~Hz}, 1 \mathrm{H}), 2.55 \sim 2.58(\mathrm{~m}, 1 \mathrm{H}), 2.81 \sim 2.84$ $(\mathrm{m}, 1 \mathrm{H}), 7.37(\mathrm{~d}, J=8.6 \mathrm{~Hz}, 2 \mathrm{H}), 7.41(\mathrm{~d}, J=8.6 \mathrm{~Hz}, 2 \mathrm{H})$, $7.47(\mathrm{~s}, 1 \mathrm{H}) ;{ }^{13} \mathrm{C}$ NMR $\left(150 \mathrm{MHz}, \mathrm{CDCl}_{3}\right) \delta: 24.1,24.7$, 25.5, 25.7, 28.4, 30.3, 31.7, 37.6, 41.7, 44.8, 48.1, 55.6, $63.0,128.7,131.8,134.4,134.5,135.2,135.8,202.6$; MS $(70 \mathrm{eV}) \mathrm{m} / z(\%): 342\left(\mathrm{M}^{+}, 90\right), 327$ (23), 299 (100).

7-(4'-Bromobenzylidene)-isolongifolanone (2b): Yellow crystal, yield $91.8 \%$. m.p. $131.7 \sim 132.2{ }^{\circ} \mathrm{C} \quad$ (lit. $^{[26]}$ $\left.129.7 \sim 130.2{ }^{\circ} \mathrm{C}\right) ;{ }^{1} \mathrm{H}$ NMR $\left(600 \mathrm{MHz}, \mathrm{CDCl}_{3}\right) \delta: 0.85(\mathrm{~s}$, $3 \mathrm{H}), 0.87(\mathrm{~s}, 3 \mathrm{H}), 1.08(\mathrm{~s}, 3 \mathrm{H}), 1.09 \sim 1.13(\mathrm{~m}, 1 \mathrm{H}), 1.24$ $(\mathrm{s}, 3 \mathrm{H}), 1.31(\mathrm{~d}, J=10.3 \mathrm{~Hz}, 1 \mathrm{H}), 1.49 \sim 1.55(\mathrm{~m}, 1 \mathrm{H})$, $1.63 \sim 1.68(\mathrm{~m}, 1 \mathrm{H}), 1.78 \sim 1.80(\mathrm{~m}, 2 \mathrm{H}), 1.82 \sim 1.87(\mathrm{~m}$, $1 \mathrm{H}), 1.99(\mathrm{~d}, J=1.8 \mathrm{~Hz}, 1 \mathrm{H}), 2.54 \sim 2.57(\mathrm{~m}, 1 \mathrm{H}), 2.79 \sim$ $2.82(\mathrm{~m}, 1 \mathrm{H}), 7.33(\mathrm{~d}, J=8.4 \mathrm{~Hz}, 2 \mathrm{H}), 7.44(\mathrm{~s}, 1 \mathrm{H}), 7.52$ $(\mathrm{d}, J=8.4 \mathrm{~Hz}, 2 \mathrm{H}) ;{ }^{13} \mathrm{C} \mathrm{NMR}\left(150 \mathrm{MHz}, \mathrm{CDCl}_{3}\right) \delta: 24.1$, 24.7, 25.5, 25.7, 28.4, 30.3, 31.7, 37.6, 41.6, 44.8, 48.1, $55.5,63.0,122.8,131.6,131.9,132.0,132.2,134.8,135.2$, 136.0, 202.6; MS (70 eV) m/z (\%): $387\left(\mathrm{M}^{+}, 42\right), 372$ (5), 345 (100).

7-(4'-Fluorobenzylidene)-isolongifolanone (2c): White crystal, yield $92.4 \%$. m.p. $141.7 \sim 142.3{ }^{\circ} \mathrm{C} \quad$ (lit. $^{[26]}$ $\left.139.7 \sim 140.3{ }^{\circ} \mathrm{C}\right) ;{ }^{1} \mathrm{H} \mathrm{NMR}\left(500 \mathrm{MHz}, \mathrm{CDCl}_{3}\right) \delta: 0.85(\mathrm{~s}$, $3 \mathrm{H}), 0.87(\mathrm{~s}, 3 \mathrm{H}), 1.07(\mathrm{~s}, 3 \mathrm{H}), 1.10 \sim 1.13(\mathrm{~m}, 1 \mathrm{H}), 1.24$ $(\mathrm{s}, 3 \mathrm{H}), 1.31(\mathrm{~d}, J=10.0 \mathrm{~Hz}, 1 \mathrm{H}), 1.48 \sim 1.55(\mathrm{~m}, 1 \mathrm{H})$, $1.63 \sim 1.68(\mathrm{~m}, 1 \mathrm{H}), 1.78 \sim 1.81(\mathrm{~m}, 2 \mathrm{H}), 1.83 \sim 1.87(\mathrm{~m}$, $1 \mathrm{H}), 1.99(\mathrm{~d}, J=1.9 \mathrm{~Hz}, 1 \mathrm{H}), 2.56 \sim 2.59(\mathrm{~m}, 1 \mathrm{H}), 2.81 \sim$ $2.84(\mathrm{~m}, 1 \mathrm{H}), 7.08(\mathrm{t}, J=9.1 \mathrm{~Hz}, 2 \mathrm{H}), 7.47(\mathrm{dd}, J=8.7,6.1$ $\mathrm{Hz}, 2 \mathrm{H}), 7.49(\mathrm{~s}, 1 \mathrm{H}) ;{ }^{13} \mathrm{C} \mathrm{NMR}\left(125 \mathrm{MHz}, \mathrm{CDCl}_{3}\right) \delta$ : 24.1, 24.6, 25.5, 25.7, 28.3, 30.3, 31.7, 37.6, 41.6, 44.7, $48.1,55.5,62.9,115.4\left(\mathrm{~d}, J_{\mathrm{C}-\mathrm{F}}=10.6 \mathrm{~Hz}, 1 \mathrm{C}\right), 132.1(\mathrm{~d}$, $\left.J_{\mathrm{C}-\mathrm{F}}=3.7 \mathrm{~Hz}, 1 \mathrm{C}\right), 132.4\left(\mathrm{~d}, J_{\mathrm{C}-\mathrm{F}}=8.6 \mathrm{~Hz}, 1 \mathrm{C}\right), 135.0(\mathrm{~d}$, $\left.J_{\mathrm{C}-\mathrm{F}}=2.2 \mathrm{~Hz}, 1 \mathrm{C}\right), 135.3\left(\mathrm{~d}, J_{\mathrm{C}-\mathrm{F}}=3.3 \mathrm{~Hz}, 1 \mathrm{C}\right), 162.6(\mathrm{~d}$, $\left.J_{\mathrm{C}-\mathrm{F}}=248.7 \mathrm{~Hz}, 1 \mathrm{C}\right), 202.4$; MS $(70 \mathrm{eV}) \mathrm{m} / \mathrm{z}(\%): 326$ $\left(\mathrm{M}^{+}, 84\right), 311(23), 283$ (100).

7-(4'-Methylbenzylidene)-isolongifolanone (2d): Yellow crystal, yield 92.3\%. m.p. $121.4 \sim 122.1{ }^{\circ} \mathrm{C} \quad$ (lit. $^{[26]}$ $\left.120.4 \sim 121.2{ }^{\circ} \mathrm{C}\right) ;{ }^{1} \mathrm{H} \mathrm{NMR}\left(600 \mathrm{MHz}, \mathrm{CDCl}_{3}\right) \delta: 0.85(\mathrm{~s}$, $3 \mathrm{H}), 0.88(\mathrm{~s}, 3 \mathrm{H}), 1.06(\mathrm{~s}, 3 \mathrm{H}), 1.09 \sim 1.13(\mathrm{~m}, 1 \mathrm{H}), 1.24$ $(\mathrm{s}, 3 \mathrm{H}), 1.30(\mathrm{~d}, J=9.9 \mathrm{~Hz}, 1 \mathrm{H}), 1.48 \sim 1.54(\mathrm{~m}, 1 \mathrm{H})$, $1.63 \sim 1.65(\mathrm{~m}, 1 \mathrm{H}), 1.77(\mathrm{~d}, J=4.1 \mathrm{~Hz}, 1 \mathrm{H}), 1.80 \sim 1.87$ $(\mathrm{m}, 2 \mathrm{H}), 1.98(\mathrm{~d}, J=1.9 \mathrm{~Hz}, 1 \mathrm{H}), 2.38(\mathrm{~s}, 3 \mathrm{H}), 2.61 \sim 2.64$ $(\mathrm{m}, 1 \mathrm{H}), 2.83 \sim 2.87(\mathrm{~m}, 1 \mathrm{H}), 7.21(\mathrm{~d}, J=8.0 \mathrm{~Hz}, 2 \mathrm{H})$, $7.40(\mathrm{~d}, J=8.0 \mathrm{~Hz}, 2 \mathrm{H}), 7.50(\mathrm{~s}, 1 \mathrm{H}) ;{ }^{13} \mathrm{C} \mathrm{NMR}(150 \mathrm{MHz}$, $\left.\mathrm{CDCl}_{3}\right) \delta: 21.4,24.1,24.7,25.5,25.8,28.4,30.3,31.7$, 37.6, 41.8, 44.8, 48.1, 55.6, 63.0, 129.2, 130.7, 133.1, 134.6, 136.6, 138.9, 202.9; MS (70 eV) $m / z(\%): 322\left(\mathrm{M}^{+}\right.$, 59), 307 (100), 279 (37).

7-(4'-Methoxybenzylidene)-isolongifolanone (2e): Yel- 
low crystal, yield $86.8 \%$. m.p. $113.5 \sim 114.2{ }^{\circ} \mathrm{C}$ (lit. ${ }^{[26]}$ $\left.112.4 \sim 113.1{ }^{\circ} \mathrm{C}\right) ;{ }^{1} \mathrm{H}$ NMR $\left(600 \mathrm{MHz}, \mathrm{CDCl}_{3}\right) \delta: 0.86(\mathrm{~s}$, $3 \mathrm{H}), 0.87(\mathrm{~s}, 3 \mathrm{H}), 1.07(\mathrm{~s}, 3 \mathrm{H}), 1.09 \sim 1.13(\mathrm{~m}, 1 \mathrm{H}), 1.24$ $(\mathrm{s}, 3 \mathrm{H}), 1.30(\mathrm{~d}, J=9.9 \mathrm{~Hz}, 1 \mathrm{H}), 1.48 \sim 1.54(\mathrm{~m}, 1 \mathrm{H})$, $1.63 \sim 1.68(\mathrm{~m}, 1 \mathrm{H}), 1.77(\mathrm{~d}, J=4.0 \mathrm{~Hz}, 1 \mathrm{H}), 1.80 \sim 1.86$ $(\mathrm{m}, 2 \mathrm{H}), 1.98(\mathrm{~d}, J=1.5 \mathrm{~Hz}, 1 \mathrm{H}), 2.60 \sim 2.63(\mathrm{~m}, 1 \mathrm{H})$, $2.83 \sim 2.86(\mathrm{~m}, 1 \mathrm{H}), 3.85\left(\mathrm{~s}, 3 \mathrm{H}, \mathrm{Ar}-\mathrm{OCH}_{3}\right), 6.93(\mathrm{~d}, J=$ $8.7 \mathrm{~Hz}, 2 \mathrm{H}), 7.47$ (s, 1H), $7.48 \sim 7.49(\mathrm{~m}, 2 \mathrm{H}) ;{ }^{13} \mathrm{C} \mathrm{NMR}$ $\left(150 \mathrm{MHz}, \mathrm{CDCl}_{3}\right) \delta: 24.2,24.7,25.5,25.8,28.4,30.2$, 31.7, 37.6, 41.9, 44.7, 48.1, 55.3, 55.5, 62.9, 113.9, 128.6, 132.5, 133.3, 136.4, 159.9, 202.8; MS (70 eV) $m / z(\%)$ : $338\left(\mathrm{M}^{+}, 100\right), 323$ (21), 295 (31).

7-Benzylidene-isolongifolanone (2f): Yellow crystal, yield 88.1\%. m.p. 96.1 96.8 ${ }^{\circ} \mathrm{C}$ (lit. ${ }^{[26]} 94.1 \sim 95.0{ }^{\circ} \mathrm{C}$ ); ${ }^{1} \mathrm{H}$ NMR (600 MHz, $\left.\mathrm{CDCl}_{3}\right) \delta: 0.86(\mathrm{~s}, 3 \mathrm{H}), 0.88(\mathrm{~s}, 3 \mathrm{H})$, $1.06(\mathrm{~s}, 3 \mathrm{H}), 1.09 \sim 1.13(\mathrm{~m}, 1 \mathrm{H}), 1.24(\mathrm{~s}, 3 \mathrm{H}), 1.31(\mathrm{~d}, J=$ $9.9 \mathrm{~Hz}, 1 \mathrm{H}), 1.48 \sim 1.55(\mathrm{~m}, 1 \mathrm{H}), 1.63 \sim 1.67(\mathrm{~m}, 1 \mathrm{H}), 1.78$ $(\mathrm{d}, J=4.2 \mathrm{~Hz}, 1 \mathrm{H}), 1.80 \sim 1.87(\mathrm{~m}, 2 \mathrm{H}), 1.99(\mathrm{~d}, J=1.9$ $\mathrm{Hz}, 1 \mathrm{H}), 2.61 \sim 2.64(\mathrm{~m}, 1 \mathrm{H}), 2.85 \sim 2.88(\mathrm{~m}, 1 \mathrm{H}), 7.32 \sim$ $7.35(\mathrm{~m}, 1 \mathrm{H}), 7.39 \sim 7.42(\mathrm{~m}, 2 \mathrm{H}), 7.49(\mathrm{~s}, J=7.5 \mathrm{~Hz}, 2 \mathrm{H})$, $7.53(\mathrm{~s}, 1 \mathrm{H}) ;{ }^{13} \mathrm{C} \mathrm{NMR}\left(150 \mathrm{MHz}, \mathrm{CDCl}_{3}\right) \delta: 24.1,24.7$, 25.5, 25.7, 28.4, 30.3, 31.7, 37.6, 41.7, 44.8, 48.1, 55.6, 63.0, 128.4, 128.6, 130.6, 135.4, 136.0, 136.6, 202.8; EIMS $m / z(\%): 308\left(\mathrm{M}^{+}, 100\right), 293$ (17), 279 (4), 265 (64), 251 (21), 197 (13), 128 (10), 116 (45), 91 (35), 77 (14), 55 (15).

7-(Pyridine-2'-ylmethylene)-isolongifolanone (2g): Yellow crystal, yield $67.5 \%$. m.p. $101.2 \sim 102.0{ }^{\circ} \mathrm{C}$ (lit. ${ }^{[28]}$ $\left.102.5 \sim 102.6{ }^{\circ} \mathrm{C}\right) ;{ }^{1} \mathrm{H} \mathrm{NMR}\left(400 \mathrm{MHz}, \mathrm{CDCl}_{3}\right) \delta: 0.85(\mathrm{~s}$, $2 \mathrm{H}), 1.06(\mathrm{~s}, 3 \mathrm{H}), 1.09 \sim 1.16(\mathrm{~m}, 1 \mathrm{H}), 1.22(\mathrm{~s}, 3 \mathrm{H}), 1.26 \sim$ $1.30(\mathrm{~m}, 1 \mathrm{H}), 1.45 \sim 1.53(\mathrm{~m}, 1 \mathrm{H}), 1.61 \sim 1.68(\mathrm{~m}, 1 \mathrm{H})$, $1.74(\mathrm{~d}, J=4 \mathrm{~Hz}), 1.80 \sim 1.83(\mathrm{~m}, 2 \mathrm{H}), 1.99(\mathrm{~s}, 1 \mathrm{H})$, $2.97 \sim 3.02(\mathrm{~m}, 1 \mathrm{H}), 3.10 \sim 3.15(\mathrm{~m}, 1 \mathrm{H}), 7.15(\mathrm{t}, J=4 \mathrm{~Hz}$, 1H), 7.39 (d, $J=4 \mathrm{~Hz}, 2 \mathrm{H}), 7.66(\mathrm{t}, J=8 \mathrm{~Hz}, 1 \mathrm{H}), 8.67$ (d, $J=4 \mathrm{~Hz}, 1 \mathrm{H}) ;{ }^{13} \mathrm{C} \mathrm{NMR}\left(100 \mathrm{MHz}, \mathrm{CDCl}_{3}\right) \delta: 24.1,24.5$, $25.3,25.4,28.1,30.1,31.1,37.5,41.6,44.6,47.9,55.5$, $62.9,122.1,126.9,133.4,135.9,139.4,149.3,155.4$, 203.4; HRMS calcd for $\mathrm{C}_{21} \mathrm{H}_{28} \mathrm{NO}[\mathrm{M}+\mathrm{H}]^{+}$310.2171, found 310.2178 .

7-(2'-Chlorobenzylidene)-isolongifolanone (2h): White solid, yield 90.5\%. m.p. 88.2 89.1 ${ }^{\circ} \mathrm{C} ;{ }^{1} \mathrm{H}$ NMR (400 $\left.\mathrm{MHz}, \mathrm{CDCl}_{3}\right) \delta: 7.66(\mathrm{~s}, 1 \mathrm{H}), 7.46 \sim 7.43(\mathrm{~m}, 1 \mathrm{H}), 7.36 \sim$ $7.33(\mathrm{~m}, 1 \mathrm{H}), 7.28(\mathrm{~s}, 2 \mathrm{H}), 2.69(\mathrm{~d}, J=16.56 \mathrm{~Hz}, 1 \mathrm{H}), 2.42$ $(\mathrm{d}, J=16.6 \mathrm{~Hz}, 1 \mathrm{H}), 2.01(\mathrm{~s}, 1 \mathrm{H}), 1.89 \sim 1.82(\mathrm{~m}, 1 \mathrm{H})$, $1.82(\mathrm{~s}, 1 \mathrm{H}), 1.65$ (dd, $J=11.76,3.56 \mathrm{~Hz}, 1 \mathrm{H}), 1.59$ (s, $1 \mathrm{H}), 1.56 \sim 1.50(\mathrm{~m}, 1 \mathrm{H}), 1.32(\mathrm{~s}, 1 \mathrm{H}), 1.27(\mathrm{~s}, 3 \mathrm{H}), 1.16 \sim$ $1.09(\mathrm{~m}, 1 \mathrm{H}), 1.01(\mathrm{~s}, 3 \mathrm{H}), 0.96(\mathrm{~s}, 3 \mathrm{H}), 0.87(\mathrm{~s}, 3 \mathrm{H}) ;{ }^{13} \mathrm{C}$ NMR $\left(100 \mathrm{MHz}, \mathrm{CDCl}_{3}\right) \delta: 202.7,137.5,135.1,134.7$, $133.8,130.4,129.8,129.5,126.4,63.3,55.9,48.4,45.0$, $40.9,37.8,32.0,30.6,28.5,25.8,25.7,24.8,24.2$; HRMS calcd for $\mathrm{C}_{22} \mathrm{H}_{28} \mathrm{ClO}[\mathrm{M}+\mathrm{H}]^{+}$343.1829, found 343.1833.

7-(2'-Bromobenzylidene)-isolongifolanone (2i): White solid, yield 95.6\%. m.p. 97.4 98.0 ${ }^{\circ} \mathrm{C} ;{ }^{1} \mathrm{H}$ NMR (400 $\left.\mathrm{MHz}, \mathrm{CDCl}_{3}\right) \delta: 7.64(\mathrm{~d}, J=8.0 \mathrm{~Hz}, 1 \mathrm{H}), 7.57(\mathrm{~s}, 1 \mathrm{H})$, $7.33(\mathrm{~d}, J=7.32 \mathrm{~Hz}, 1 \mathrm{H}), 7.28(\mathrm{~s}, 1 \mathrm{H}), 7.20$ (t, $J=7.04 \mathrm{~Hz}$, $1 \mathrm{H}), 2.64$ (d, $J=16.72 \mathrm{~Hz}, 1 \mathrm{H}), 2.39$ (d, $J=16.6 \mathrm{~Hz}, 1 \mathrm{H})$, $2.01(\mathrm{~s}, 1 \mathrm{H}), 1.87 \sim 1.84(\mathrm{~m}, 1 \mathrm{H}), 1.82(\mathrm{~s}, 1 \mathrm{H}), 1.69 \sim 1.63$ $(\mathrm{m}, 1 \mathrm{H}), 1.59(\mathrm{~s}, 1 \mathrm{H}), 1.56 \sim 1.49(\mathrm{~m}, 1 \mathrm{H}), 1.32(\mathrm{~s}, 1 \mathrm{H})$, $1.27(\mathrm{~s}, 3 \mathrm{H}), 1.16 \sim 1.09(\mathrm{~m}, 1 \mathrm{H}), 1.00(\mathrm{~s}, 3 \mathrm{H}), 0.97(\mathrm{~s}, 3 \mathrm{H})$, $0.88(\mathrm{~s}, 3 \mathrm{H}) ;{ }^{13} \mathrm{C}$ NMR $\left(100 \mathrm{MHz}, \mathrm{CDCl}_{3}\right) \delta: 202.8,137.3$, 136.6, 136.2, 133.0, 130.4, 129.6, 127.0, 125.1, 63.3, 55.9, $48.3,45.0,40.7,37.8,32.0,30.6,28.5,25.8,25.7,24.8$, 24.2; HRMS calcd for $\mathrm{C}_{22} \mathrm{H}_{28} \mathrm{BrO}[\mathrm{M}+\mathrm{H}]^{+}$387.1324, found 387.1326 .

7-(2'-Fluorobenzylidene)-isolongifolanone (2j): White solid, yield 93\%. m.p. 106.4 107.1 ${ }^{\circ} \mathrm{C}$; ${ }^{1} \mathrm{H}$ NMR (400 $\left.\mathrm{MHz}, \mathrm{CDCl}_{3}\right) \delta: 7.65(\mathrm{~s}, 1 \mathrm{H}), 7.43(\mathrm{t}, J=7.48 \mathrm{~Hz}, 1 \mathrm{H})$, 7.34 (q, $J=7.4 \mathrm{~Hz}, 1 \mathrm{H}), 7.18(\mathrm{t}, J=7.44 \mathrm{~Hz}, 1 \mathrm{H}), 7.11(\mathrm{t}$, $J=8.76 \mathrm{~Hz}, 1 \mathrm{H}), 2.79(\mathrm{~d}, J=16.84 \mathrm{~Hz}, 1 \mathrm{H}), 2.48(\mathrm{~d}, J=$ $16.76 \mathrm{~Hz}, 1 \mathrm{H}), 2.01(\mathrm{~s}, 1 \mathrm{H}), 1.87 \sim 1.85(\mathrm{~m}, 1 \mathrm{H}), 1.81(\mathrm{~d}$, $J=3.84 \mathrm{~Hz}, 1 \mathrm{H}), 1.67$ (td, $J=3.6,3.56 \mathrm{~Hz}, 1 \mathrm{H}), 1.60$ (s, $1 \mathrm{H}), 1.58 \sim 1.51(\mathrm{~m}, 1 \mathrm{H}), 1.32(\mathrm{~d}, J=9.84 \mathrm{~Hz}, 1 \mathrm{H}), 1.27$ $(\mathrm{s}, 3 \mathrm{H}), 1.16 \sim 1.10(\mathrm{~m}, 1 \mathrm{H}), 1.05(\mathrm{~s}, 3 \mathrm{H}), 0.93(\mathrm{~s}, 3 \mathrm{H})$, $0.87(\mathrm{~s}, 3 \mathrm{H}) ;{ }^{13} \mathrm{C}$ NMR $\left(100 \mathrm{MHz}, \mathrm{CDCl}_{3}\right) \delta: 202.3,161.2$ $\left(\mathrm{d}, J_{\mathrm{C}-\mathrm{F}}=249.57 \mathrm{~Hz}, 1 \mathrm{C}\right), 137.5,130.6\left(\mathrm{~d}, J_{\mathrm{C}-\mathrm{F}}=2.82 \mathrm{~Hz}\right.$, 1C), $130.3\left(\mathrm{~d}, J_{\mathrm{C}-\mathrm{F}}=8.48 \mathrm{~Hz}, 1 \mathrm{C}\right), 129.2\left(\mathrm{~d}, J_{\mathrm{C}-\mathrm{F}}=4.07\right.$ $\mathrm{Hz}, 1 \mathrm{C}), 124.1$ (d, $\left.J_{\mathrm{C}-\mathrm{F}}=13.3 \mathrm{~Hz}, 1 \mathrm{C}\right), 123.8\left(\mathrm{~d}, J_{\mathrm{C}-\mathrm{F}}=\right.$ $3.63 \mathrm{~Hz}, 1 \mathrm{C}), 115.9\left(\mathrm{~d}, J_{\mathrm{C}-\mathrm{F}}=22.01 \mathrm{~Hz}, 1 \mathrm{C}\right), 63.2,55.9$, $48.3,45.0,41.4,37.8,31.9,30.6,28.5,25.8,25.8,24.8$, 24.2; HRMS calcd for $\mathrm{C}_{22} \mathrm{H}_{28} \mathrm{FO}[\mathrm{M}+\mathrm{H}]^{+} 327.2124$, found 327.2121 .

7-(2'-Methylbenzylidene)-isolongifolanone (2k): White solid, yield 90.7\%. m.p. 85.2 85.9 ${ }^{\circ} \mathrm{C} ;{ }^{1} \mathrm{H}$ NMR (400 $\left.\mathrm{MHz}, \mathrm{CDCl}_{3}\right) \delta: 7.69(\mathrm{~s}, 1 \mathrm{H}), 7.28(\mathrm{~s}, 1 \mathrm{H}), 7.24(\mathrm{~s}, 3 \mathrm{H})$, $2.68(\mathrm{~d}, J=16.52 \mathrm{~Hz}, 1 \mathrm{H}), 2.45(\mathrm{~d}, J=16.48 \mathrm{~Hz}, 1 \mathrm{H}), 2.31$ $(\mathrm{s}, 3 \mathrm{H}), 1.99(\mathrm{~s}, 1 \mathrm{H}), 1.86(\mathrm{~s}, 1 \mathrm{H}), 1.81(\mathrm{~s}, 1 \mathrm{H}), 1.66(\mathrm{td}$, $J=3.56,3.44 \mathrm{~Hz}, 1 \mathrm{H}), 1.61(\mathrm{~s}, 1 \mathrm{H}), 1.53$ (tt, $J=4.6,3.12$ $\mathrm{Hz}, 1 \mathrm{H}), 1.32(\mathrm{~s}, 1 \mathrm{H}), 1.28(\mathrm{~s}, 3 \mathrm{H}), 1.13 \sim 1.10(\mathrm{~m}, 1 \mathrm{H})$, $1.00(\mathrm{~s}, 3 \mathrm{H}), 0.96(\mathrm{~s}, 3 \mathrm{H}), 0.85(\mathrm{~s}, 3 \mathrm{H}) ;{ }^{13} \mathrm{C}$ NMR $(100$ $\left.\mathrm{MHz} \mathrm{CDCl}_{3}\right) \delta: 202.8,138.0,136.1,135.9,135.3,130.3$, $128.9,128.4,125.5,63.3,55.9,48.4,44.9,40.7,37.8,32.0$, $30.7,28.5,25.8,25.7,24.8,24.0,20.1$; HRMS calcd for $\mathrm{C}_{23} \mathrm{H}_{31} \mathrm{O}[\mathrm{M}+\mathrm{H}]^{+}$323.2375, found 323.2370.

7-(2'-Methoxybenzylidene)-isolongifolanone (2l): White solid, yield 91.3\%. m.p. 102.8 103.3 ${ }^{\circ} \mathrm{C} ;{ }^{1} \mathrm{H}$ NMR (400 $\left.\mathrm{MHz}, \mathrm{CDCl}_{3}\right) \delta: 7.85(\mathrm{~s}, 1 \mathrm{H}), 7.39(\mathrm{~d}, J=7.6 \mathrm{~Hz}, 1 \mathrm{H})$, $7.33(\mathrm{t}, J=7.52 \mathrm{~Hz}, 1 \mathrm{H}), 6.98(\mathrm{t}, J=7.44 \mathrm{~Hz}, 1 \mathrm{H}), 6.92$ (d, $J=8.28 \mathrm{~Hz}, 1 \mathrm{H}), 3.86(\mathrm{~s}, 3 \mathrm{H}), 2.80(\mathrm{~d}, J=16.64 \mathrm{~Hz}, 1 \mathrm{H})$, $2.56(\mathrm{~d}, J=16.64 \mathrm{~Hz}, 1 \mathrm{H}), 1.99$ (s, 1H), 1.85 (d, $J=10.28$ $\mathrm{Hz}, 2 \mathrm{H}), 1.79(\mathrm{~d}, J=3.96 \mathrm{~Hz}, 1 \mathrm{H}), 1.67 \sim 1.63(\mathrm{~m}, 1 \mathrm{H})$, $1.57 \sim 1.50(\mathrm{~m}, 1 \mathrm{H}), 1.31(\mathrm{~d}, J=9.88 \mathrm{~Hz}, 1 \mathrm{H}), 1.27(\mathrm{~s}$, $3 \mathrm{H}), 1.15 \sim 1.09(\mathrm{~m}, 1 \mathrm{H}), 1.04(\mathrm{~s}, 3 \mathrm{H}), 0.93(\mathrm{~s}, 3 \mathrm{H}), 0.86$ $(\mathrm{s}, 3 \mathrm{H}) ;{ }^{13} \mathrm{C}$ NMR $\left(100 \mathrm{MHz}, \mathrm{CDCl}_{3}\right) \delta: 202.7,158.7$, $135.1,132.3,130.2,130.1,125.1,120.0,110.8,63.2,55.8$, 55.7, 48.3, 44.9, 41.4, 37.8, 32.00, 30.6, 28.5, 25.8, 25.8, 24.8, 24.1; HRMS calcd for $\mathrm{C}_{23} \mathrm{H}_{31} \mathrm{O}_{2}[\mathrm{M}+\mathrm{H}]^{+}$339.2324, found 339.2325 .

\subsubsection{Synthesis of compounds $\mathbf{3 a} \sim \mathbf{3 1}$}

To a solution of $6 \mathrm{mmol}$ of $\mathbf{2 a} \sim \mathbf{2 l}$ in $40 \mathrm{~mL}$ of ethanol and $60 \mathrm{~mL}$ of tert-butyl alcohol were added $7 \mathrm{mmol}$ of thiourea and potassium tert-butoxide, then the mixture was refluxed and stirred for $30 \mathrm{~h}$. After the reaction was completed, the $50 \mathrm{~mL}$ of saturated brine was poured into mix- 
ture, and then extracted three times with ethyl acetate (50 $\mathrm{mL} \times 3$ ) to neutrality, dried by anhydrous $\mathrm{Na}_{2} \mathrm{SO}_{4}$. After filtered and concentrated under reduced pressure, the residues were purified by chromatography on silica gel to afford $\mathbf{3 a} \sim \mathbf{3 1}$.

(4S,6aR,9R,10aR)-4-(4-Chlorophenyl)-6,6,10,10-tetramethyl-4,5,6,7,8,9,10,10a-octahydro-1H-6a,9-methanobenzo $[h]$ quinazoline-2(3H)-thione (3a): White powder, yield $65.4 \%$, purity $98.8 \%$. m.p. $208.4 \sim 209.1{ }^{\circ} \mathrm{C} ;{ }^{1} \mathrm{H}$ NMR (400 MHz, $\left.\mathrm{CDCl}_{3}\right) \delta: 7.32(\mathrm{~s}, 1 \mathrm{H}), 7.30(\mathrm{~s}, 1 \mathrm{H}), 7.27$ $(\mathrm{s}, 1 \mathrm{H}), 7.19(\mathrm{~s}, 1 \mathrm{H}), 7.17(\mathrm{~s}, 1 \mathrm{H}), 6.85(\mathrm{~s}, 1 \mathrm{H}), 4.72(\mathrm{~s}$, $1 \mathrm{H}), 2.18(\mathrm{~s}, 1 \mathrm{H}), 1.83(\mathrm{~s}, 1 \mathrm{H}), 1.65$ (t, $J=10.08 \mathrm{~Hz}, 1 \mathrm{H})$, $1.51(\mathrm{dd}, J=3.72,3.68 \mathrm{~Hz}, 1 \mathrm{H}), 1.41(\mathrm{~d}, J=9.32 \mathrm{~Hz}, 1 \mathrm{H})$, $1.35(\mathrm{~d}, J=12.04 \mathrm{~Hz}, 1 \mathrm{H}), 1.30(\mathrm{~s}, 1 \mathrm{H}), 1.26 \sim 1.20(\mathrm{~m}$, $2 \mathrm{H}), 1.14$ (s, 3H), 1.13 (s, 3H), 1.01 (d, $J=11.84 \mathrm{~Hz}, 1 \mathrm{H})$, $0.89(\mathrm{~s}, 3 \mathrm{H}), 0.83(\mathrm{~s}, 3 \mathrm{H}) ;{ }^{13} \mathrm{C}$ NMR $\left(100 \mathrm{MHz}, \mathrm{CDCl}_{3}\right) \delta$ : $173.0(\mathrm{~s}, 1 \mathrm{C}, \mathrm{C}=\mathrm{S}), 140.4,134.3,129.3,128.4,127.4$, 108.1, 60.9, 55.7, 51.1, 50.9, 40.4, 37.2, 36.0, 34.0, 32.8, 26.2, 24.6, 24.4, 24.1, 22.8; HRMS calcd for $\mathrm{C}_{23} \mathrm{H}_{30} \mathrm{ClN}_{2} \mathrm{~S}$ $[\mathrm{M}+\mathrm{H}]^{+}$401.1818, found 401.1818.

(4S,6aR,9R,10aR)-4-(4-Bromophenyl)-6,6,10,10-tetramethyl-4,5,6,7,8,9,10,10a-octahydro-1H-6a,9-methanobenzo $[h]$ quinazoline-2 $(3 H)$-thione $(\mathbf{3 b})$ : White powder, yield $66.7 \%$, purity $99.0 \%$. m.p. $218.2 \sim 218.9{ }^{\circ} \mathrm{C} ;{ }^{1} \mathrm{H}$ NMR (400 MHz, $\left.\mathrm{CDCl}_{3}\right) \delta: 7.50(\mathrm{~s}, 1 \mathrm{H}), 7.48(\mathrm{~s}, 1 \mathrm{H}), 7.15$ $(\mathrm{s}, 1 \mathrm{H}), 7.13(\mathrm{~s}, 1 \mathrm{H}), 6.91(\mathrm{~s}, 1 \mathrm{H}), 6.77(\mathrm{~s}, 1 \mathrm{H}), 4.72(\mathrm{~s}$, $1 \mathrm{H}), 2.20(\mathrm{~s}, 1 \mathrm{H}), 1.85(\mathrm{~s}, 1 \mathrm{H}), 1.52(\mathrm{dd}, J=3.88,3.76 \mathrm{~Hz}$, $1 \mathrm{H}), 1.42(\mathrm{~d}, J=9.28 \mathrm{~Hz}, 1 \mathrm{H}), 1.38 \sim 1.32(\mathrm{~m}, 2 \mathrm{H}), 1.26(\mathrm{~d}$, $J=11.72 \mathrm{~Hz}, 2 \mathrm{H}), 1.22(\mathrm{~s}, 1 \mathrm{H}), 1.16(\mathrm{~s}, 3 \mathrm{H}), 1.15$ (s, 3H), $1.04(\mathrm{~d}, J=10.32 \mathrm{~Hz}, 1 \mathrm{H}), 0.91(\mathrm{~s}, 3 \mathrm{H}), 0.84(\mathrm{~s}, 3 \mathrm{H}) ;{ }^{13} \mathrm{C}$ NMR $\left(100 \mathrm{MHz}, \mathrm{CDCl}_{3}\right) \delta: 173.4(\mathrm{~s}, 1 \mathrm{C}, \mathrm{C}=\mathrm{S}), 141.0$, $132.3,128.7,127.5,122.7,108.1,61.2,55.7,51.2,51.0$, 40.5, 37.3, 36.1, 34.1, 32.9, 26.3, 24.6, 24.5, 24.1, 22.9; HRMS calcd for $\mathrm{C}_{23} \mathrm{H}_{30} \mathrm{BrN}_{2} \mathrm{~S}[\mathrm{M}+\mathrm{H}]^{+}$445.1313, found 445.1317 .

(4S,6aR,9R,10aR)-4-(4-Fluorophenyl)-6,6,10,10-tetramethyl-4,5,6,7,8,9,10,10a-octahydro- $1 H$-6a,9-methanobenzo $[h]$ quinazoline-2(3H)-thione $(3 \mathbf{c})$ : White powder, yield $65.8 \%$, purity $98.3 \%$. m.p. $168.2 \sim 169.0{ }^{\circ} \mathrm{C} ;{ }^{1} \mathrm{H}$ NMR $\left(400 \mathrm{MHz}, \mathrm{CDCl}_{3}\right) \delta: 7.25 \sim 7.22(\mathrm{~m}, 2 \mathrm{H}), 7.06(\mathrm{t}$, $J=8.56 \mathrm{~Hz}, 2 \mathrm{H}), 6.94(\mathrm{~s}, 1 \mathrm{H}), 6.48(\mathrm{~s}, 1 \mathrm{H}), 4.75(\mathrm{~s}, 1 \mathrm{H})$, $2.21(\mathrm{~s}, 1 \mathrm{H}), 1.86(\mathrm{~s}, 1 \mathrm{H}), 1.68(\mathrm{t}, J=11.28 \mathrm{~Hz}, 1 \mathrm{H}), 1.50$ $(\mathrm{d}, J=4.0 \mathrm{~Hz}, 1 \mathrm{H}), 1.44(\mathrm{~s}, 1 \mathrm{H}), 1.37$ (d, $J=12.0 \mathrm{~Hz}, 1 \mathrm{H})$, $1.32(\mathrm{~s}, 1 \mathrm{H}), 1.28 \sim 1.24(\mathrm{~m}, 2 \mathrm{H}), 1.17(\mathrm{~s}, 6 \mathrm{H}), 1.11(\mathrm{~d}, J=$ $19.2 \mathrm{~Hz}, 1 \mathrm{H}), 0.92$ (s, 3H), $0.85(\mathrm{~s}, 3 \mathrm{H}) ;{ }^{13} \mathrm{C}$ NMR $(100$ $\left.\mathrm{MHz}, \mathrm{CDCl}_{3}\right) \delta: 173.2(\mathrm{~s}, 1 \mathrm{C}, \mathrm{C}=\mathrm{S}), 162.8\left(\mathrm{~d}, J_{\mathrm{C}-\mathrm{F}}=\right.$ $245.81 \mathrm{~Hz}, 1 \mathrm{C}), 137.9,128.8\left(\mathrm{~d}, J_{\mathrm{C}-\mathrm{F}}=8.17 \mathrm{~Hz}, 1 \mathrm{C}\right)$, $127.4,116.1\left(\mathrm{~d}, J_{\mathrm{C}-\mathrm{F}}=21.61 \mathrm{~Hz}, 1 \mathrm{C}\right), 108.4,61.1,55.7$, $51.2,51.0,40.5,37.2,36.1,34.0,32.9,26.3,24.6,24.5$, 24.1, 22.9; HRMS calcd for $\mathrm{C}_{23} \mathrm{H}_{30} \mathrm{FN}_{2} \mathrm{~S}[\mathrm{M}+\mathrm{H}]^{+}$ 385.2114 , found 385.2112 .

$(4 S, 6 a R, 9 R, 10 a R)-4-(4-M e t h y l p h e n y l)-6,6,10,10$-tetramethyl-4,5,6,7,8,9,10,10a-octahydro-1H-6a,9-methanobenzo $[h]$ quinazoline-2 $(3 H)$-thione $(\mathbf{3 d})$ : White powder, yield $60.2 \%$, purity $97.5 \%$. m.p. $205.2 \sim 205.8{ }^{\circ} \mathrm{C} ;{ }^{1} \mathrm{H}$ NMR (400 MHz, $\left.\mathrm{CDCl}_{3}\right) \delta: 7.14(\mathrm{~s}, 4 \mathrm{H}), 6.9(\mathrm{~m}, 1 \mathrm{H}), 6.86$ $(\mathrm{s}, 1 \mathrm{H}), 4.70(\mathrm{~s}, 1 \mathrm{H}), 2.32(\mathrm{~s}, 3 \mathrm{H}), 2.19(\mathrm{~s}, 1 \mathrm{H}), 1.83$ (s,
$1 \mathrm{H}), 1.66(\mathrm{t}, J=9.80 \mathrm{~Hz}, 1 \mathrm{H}), 1.54(\mathrm{dd}, J=3.64,3.60 \mathrm{~Hz}$, $1 \mathrm{H}), 1.41(\mathrm{~d}, J=9.16 \mathrm{~Hz}, 1 \mathrm{H}), 1.32(\mathrm{~d}, J=11.96 \mathrm{~Hz}, 2 \mathrm{H})$, $1.26 \sim 1.20(\mathrm{~m}, 2 \mathrm{H}), 1.16(\mathrm{~s}, 3 \mathrm{H}), 1.15(\mathrm{~s}, 3 \mathrm{H}), 1.09(\mathrm{~d}, J=$ $9.48 \mathrm{~Hz}, 1 \mathrm{H}), 0.89$ (s, 3H), $0.82(\mathrm{~s}, 3 \mathrm{H}) ;{ }^{13} \mathrm{C}$ NMR $(100$ $\left.\mathrm{MHz}, \mathrm{CDCl}_{3}\right) \delta: 173.2(\mathrm{~s}, 1 \mathrm{C}, \mathrm{C}=\mathrm{S}), 139.0,138.5,129.8$, 127.1, 108.6, 61.6, 55.8, 51.2, 51.0, 40.5, 37.2, 36.1, 34.1, 32.9, 26.3, 24.6, 24.5, 24.1, 22.9, 21.3; HRMS calcd for $\mathrm{C}_{24} \mathrm{H}_{33} \mathrm{~N}_{2} \mathrm{~S}[\mathrm{M}+\mathrm{H}]^{+}$381.2364, found 381.2360.

(4S,6aR,9R,10aR)-4-(4-Methoxyphenyl)-6,6,10,10-tetramethyl-4,5,6,7,8,9,10,10a-octahydro- $1 H$-6a,9-methanobenzo[ $h]$ quinazoline-2(3H)-thione (3e): White powder, yield $62.5 \%$, purity $98.4 \%$. m.p. $197.4 \sim 198.0{ }^{\circ} \mathrm{C} ;{ }^{1} \mathrm{H}$ NMR $\left(400 \mathrm{MHz}, \mathrm{CDCl}_{3}\right) \delta: 7.17(\mathrm{~s}, 1 \mathrm{H}), 7.15(\mathrm{~s}, 1 \mathrm{H}), 6.92(\mathrm{~s}$, $1 \mathrm{H}), 6.86(\mathrm{~s}, 1 \mathrm{H}), 6.84(\mathrm{~s}, 2 \mathrm{H}), 4.69(\mathrm{~s}, 1 \mathrm{H}), 3.78(\mathrm{~s}, 3 \mathrm{H})$, $2.18(\mathrm{~s}, 1 \mathrm{H}), 1.83(\mathrm{~s}, 1 \mathrm{H}), 1.66(\mathrm{t}, J=9.72 \mathrm{~Hz}, 1 \mathrm{H}), 1.53$ (dd, $J=3.68,3.68 \mathrm{~Hz}, 1 \mathrm{H}), 1.41(\mathrm{~d}, J=9.28 \mathrm{~Hz}, 1 \mathrm{H})$, $1.34 \sim 1.29(\mathrm{~m}, 2 \mathrm{H}), 1.24 \sim 1.20(\mathrm{~m}, 2 \mathrm{H}), 1.15(\mathrm{~s}, 3 \mathrm{H})$, $1.14(\mathrm{~s}, 3 \mathrm{H}), 1.10(\mathrm{~s}, 1 \mathrm{H}), 0.89(\mathrm{~s}, 3 \mathrm{H}), 0.82(\mathrm{~s}, 3 \mathrm{H}) ;{ }^{13} \mathrm{C}$ NMR $\left(100 \mathrm{MHz}, \mathrm{CDCl}_{3}\right) \delta: 172.7(\mathrm{~s}, 1 \mathrm{C}, \mathrm{C}=\mathrm{S}), 159.7$, $134.1,128.3,127.0,114.3,108.7,61.0,55.7,55.4,51.1$, 51.0, 40.4, 37.1, 36.0, 34.0, 32.8, 26.2, 24.6, 24.4, 24.0, 22.8; HRMS calcd for $\mathrm{C}_{24} \mathrm{H}_{33} \mathrm{~N}_{2} \mathrm{OS}[\mathrm{M}+\mathrm{H}]^{+}$397.2314, found 397.2310 .

$(4 S, 6 a R, 9 R, 10 a R)-6,6,10,10-$ Tetramethyl-4-phenyl-4,5, $6,7,8,9,10,10 a$-octahydro- $1 H-6 a, 9$-methanobenzo[ $h]$ quinazoline-2(3H)-thione (3f): White powder, yield 57.4\%, purity $99.4 \%$. m.p. $114.8 \sim 115.4{ }^{\circ} \mathrm{C}$; ${ }^{1} \mathrm{H}$ NMR (400 MHz, $\left.\mathrm{CDCl}_{3}\right) \delta: 7.35(\mathrm{~d}, J=6.72 \mathrm{~Hz}, 1 \mathrm{H}), 7.31(\mathrm{t}, J=6.84 \mathrm{~Hz}$, $2 \mathrm{H}), 7.26(\mathrm{~s}, 1 \mathrm{H}), 7.24(\mathrm{~s}, 1 \mathrm{H}), 6.96(\mathrm{~s}, 1 \mathrm{H}), 6.86(\mathrm{~s}, 1 \mathrm{H})$, $4.74(\mathrm{~s}, 1 \mathrm{H}), 2.20(\mathrm{~s}, 1 \mathrm{H}), 1.84(\mathrm{~s}, 1 \mathrm{H}), 1.66(\mathrm{t}, J=9.80 \mathrm{~Hz}$, $1 \mathrm{H}), 1.54(\mathrm{dd}, J=3.92,3.92 \mathrm{~Hz}, 1 \mathrm{H}), 1.41(\mathrm{~d}, J=9.6 \mathrm{~Hz}$, $1 \mathrm{H}), 1.33 \sim 1.28(\mathrm{~m}, 2 \mathrm{H}), 1.27 \sim 1.23(\mathrm{~m}, 1 \mathrm{H}), 1.22 \sim 1.18$ $(\mathrm{m}, 1 \mathrm{H}), 1.16(\mathrm{~s}, 3 \mathrm{H}), 1.15(\mathrm{~s}, 3 \mathrm{H}), 1.12(\mathrm{~d}, J=9.6 \mathrm{~Hz}$, $1 \mathrm{H}), 0.90(\mathrm{~s}, 3 \mathrm{H}), 0.82(\mathrm{~s}, 3 \mathrm{H}) ;{ }^{13} \mathrm{C} \mathrm{NMR}(100 \mathrm{MHz}$, $\left.\mathrm{CDCl}_{3}\right) \delta: 173.1(\mathrm{~s}, 1 \mathrm{C}, \mathrm{C}=\mathrm{S}), 141.9,129.1,128.5,127.2$, 127.1, 108.4, 61.7, 55.7, 51.2, 51.0, 40.4, 37.2, 36.0, 34.0, $32.8,26.2,24.6,24.4,24.0,22.8$; HRMS calcd for $\mathrm{C}_{23} \mathrm{H}_{31} \mathrm{~N}_{2} \mathrm{~S}[\mathrm{M}+\mathrm{H}]^{+}$367.2208, found 367.2203.

$(4 S, 6 a R, 9 R, 10 a R)-4$-(Pyridin-2'-yl)-6,6,10,10-tetramethyl-4,5,6,7,8,9,10,10a-octahydro-1H-6a,9-methanobenzo$[h]$ quinazoline-2(3H)-thione $\mathbf{( 3 g )}$ : Brown solid, yield $88.5 \%$, purity $99.1 \%$. m.p. $75.1 \sim 75.9{ }^{\circ} \mathrm{C} ;{ }^{1} \mathrm{H}$ NMR $(400$ $\left.\mathrm{MHz} \mathrm{CDCl}_{3}\right) \delta: 8.48(\mathrm{~d}, J=5.72 \mathrm{~Hz}, 1 \mathrm{H}), 7.55(\mathrm{t}, J=7.64$ $\mathrm{Hz}, 1 \mathrm{H}), 7.27$ (d, $J=7.84 \mathrm{~Hz}, 1 \mathrm{H}), 7.07$ (t, $J=5.84 \mathrm{~Hz}$, $1 \mathrm{H}), 6.52(\mathrm{~s}, 1 \mathrm{H}), 3.82(\mathrm{~d}, J=13.16 \mathrm{~Hz}, 1 \mathrm{H}), 3.52$ (d, $J=$ $14.28 \mathrm{~Hz}, 1 \mathrm{H}), 1.92(\mathrm{~s}, 1 \mathrm{H}), 1.83 \sim 1.78(\mathrm{~m}, 1 \mathrm{H}), 1.69 \sim$ $1.65(\mathrm{~m}, 2 \mathrm{H}), 1.59(\mathrm{dd}, J=3.56,3.48 \mathrm{~Hz}, 1 \mathrm{H}), 1.50 \sim 1.41$ $(\mathrm{m}, 1 \mathrm{H}), 1.26 \sim 1.18(\mathrm{~m}, 2 \mathrm{H}), 1.16(\mathrm{~s}, 3 \mathrm{H}), 1.12(\mathrm{~d}, J=$ $11.76 \mathrm{~Hz}, 1 \mathrm{H}), 1.08$ (s, 3H), 0.99 (s, 3H), 0.92 (d, $J=26.16$ $\mathrm{Hz}, 1 \mathrm{H}), 0.55(\mathrm{~s}, 3 \mathrm{H}) ;{ }^{13} \mathrm{C}$ NMR $\left(100 \mathrm{MHz}, \mathrm{CDCl}_{3}\right) \delta$ : 200.1 (s, 1C, $\mathrm{C}=\mathrm{S}), 160.0,156.5,149.2,136.3,135.7$, 124.0, 121.2, 61.5, 55.5, 48.4, 44.6, 38.8, 38.7, 35.1, 30.0, 28.7, 27.2, 26.2, 25.0, 24.6; MS $m / z: 366.2[\mathrm{M}-\mathrm{H}]^{+}$. Anal. calcd for $\mathrm{C}_{22} \mathrm{H}_{29} \mathrm{~N}_{3} \mathrm{~S}$ C 71.89, H 7.95, N 11.43; found C 71.78, H 7.86, N 11.57.

(4S,6aR,9R,10aR)-4-(2-Chlorophenyl)-6,6,10,10-tetramethyl-4,5,6,7,8,9,10,10a-octahydro-1H-6a,9-methano- 
benzo[ $h]$ quinazoline-2(3H)-thione $(\mathbf{3 h})$ : White powder, yield $50.2 \%$, purity $99.5 \%$. m.p. $75.8 \sim 76.4{ }^{\circ} \mathrm{C}$; ${ }^{1} \mathrm{H}$ NMR $\left(400 \mathrm{MHz}, \mathrm{CDCl}_{3}\right) \delta: 7.39 \sim 7.34(\mathrm{~m}, 2 \mathrm{H}), 7.31(\mathrm{t}, J=7.52$ $\mathrm{Hz}, 1 \mathrm{H}), 7.26 \sim 7.22(\mathrm{~m}, 1 \mathrm{H}), 6.91(\mathrm{~s}, 1 \mathrm{H}), 6.82(\mathrm{~s}, 1 \mathrm{H})$, $5.35(\mathrm{~s}, 1 \mathrm{H}), 2.24(\mathrm{~s}, 1 \mathrm{H}), 1.86(\mathrm{~s}, 1 \mathrm{H}), 1.71(\mathrm{t}, J=9.04 \mathrm{~Hz}$, $1 \mathrm{H}), 1.62$ (dd, $J=4.0,3.92 \mathrm{~Hz}, 1 \mathrm{H}), 1.44$ (d, $J=10.08 \mathrm{~Hz}$, 2H), 1.38 (d, $J=16.08 \mathrm{~Hz}, 1 \mathrm{H}), 1.29 \sim 1.23(\mathrm{~m}, 2 \mathrm{H}), 1.18$ $(\mathrm{s}, 3 \mathrm{H}), 1.17(\mathrm{~s}, 3 \mathrm{H}), 1.14(\mathrm{~d}, J=7.36 \mathrm{~Hz}, 1 \mathrm{H}), 0.93$ (s, $3 \mathrm{H}), 0.86(\mathrm{~s}, 3 \mathrm{H}) ;{ }^{13} \mathrm{C} \mathrm{NMR}\left(100 \mathrm{MHz}, \mathrm{CDCl}_{3}\right) \delta: 202.7$ (s, $1 \mathrm{C}, \mathrm{C}=\mathrm{S}), 137.5,135.1,134.7,133.8,130.4,129.8,129.5$, $126.4,63.3,55.9,48.4,45.0,40.9,37.8,32.0,30.6,28.5$, 25.8, 25.7, 24.8, 24.2; HRMS calcd for $\mathrm{C}_{23} \mathrm{H}_{30} \mathrm{ClN}_{2} \mathrm{~S}[\mathrm{M}+$ $\mathrm{H}]^{+}$401.1818, found 401.1811 .

(4S,6aR,9R,10aR)-4-(2-Bromophenyl)-6,6,10,10-tetramethyl-4,5,6,7,8,9,10,10a-octahydro- $1 H$-6a,9-methanobenzo $[h]$ quinazoline-2 $(3 H)$-thione $(\mathbf{3 i})$ : White powder, yield $51.7 \%$, purity $98.0 \%$. m.p. $211.3 \sim 211.8{ }^{\circ} \mathrm{C} ;{ }^{1} \mathrm{H}$ NMR (400 MHz, $\left.\mathrm{CDCl}_{3}\right) \delta: 7.54(\mathrm{~d}, J=7.32 \mathrm{~Hz}, 1 \mathrm{H}), 7.39$ (dd, $J=2.28,2.08 \mathrm{~Hz}, 1 \mathrm{H}), 7.35(\mathrm{~d}, J=6.92 \mathrm{~Hz}, 1 \mathrm{H})$, $7.19 \sim 7.15(\mathrm{~m}, 1 \mathrm{H}), 6.92(\mathrm{~s}, 1 \mathrm{H}), 6.72(\mathrm{~s}, 1 \mathrm{H}), 5.34(\mathrm{~s}$, $1 \mathrm{H}), 2.24(\mathrm{~s}, 1 \mathrm{H}), 1.87(\mathrm{~s}, 1 \mathrm{H}), 1.62(\mathrm{dd}, J=3.96,3.92 \mathrm{~Hz}$, $1 \mathrm{H}), 1.46 \sim 1.37(\mathrm{~m}, 3 \mathrm{H}), 1.34 \sim 1.23(\mathrm{~m}, 3 \mathrm{H}), 1.19(\mathrm{~s}$, $3 \mathrm{H}), 1.17$ (s, 3H), 1.15 (s, 1H), 0.93 (s, 3H), 0.86 (s, 3H); ${ }^{13} \mathrm{C} \mathrm{NMR}\left(100 \mathrm{MHz} \mathrm{CDCl}_{3}\right) \delta: 173.5(\mathrm{~s}, 1 \mathrm{C}, \mathrm{C}=\mathrm{S})$, $139.8,133.3,130.2,129.63,128.78,128.72,123.00$, $107.35,60.05,55.80,51.43,50.95,40.26,37.27,36.14$, $34.04,32.94,26.32,24.58,24.48,24.2,23.1$; HRMS calcd for $\mathrm{C}_{23} \mathrm{H}_{30} \mathrm{BrN}_{2} \mathrm{~S}[\mathrm{M}+\mathrm{H}]^{+}$445.1313, found 445.1319 .

(4S,6aR,9R,10aR)-4-(2-Fluorophenyl)-6,6,10,10-tetramethyl-4,5,6,7,8,9,10,10a-octahydro- $1 H$-6a,9-methanobenzo $[h]$ quinazoline-2(3H)-thione $(\mathbf{3 j})$ : White powder, yield $50.5 \%$, purity $98.7 \%$. m.p. $104.8 \sim 105.4{ }^{\circ} \mathrm{C} ;{ }^{1} \mathrm{H}$ NMR $\left(400 \mathrm{MHz}, \mathrm{CDCl}_{3}\right) \delta: 7.33(\mathrm{dd}, J=1.60,1.52 \mathrm{~Hz}$, $1 \mathrm{H}), 7.30 \sim 7.28(\mathrm{~m}, 1 \mathrm{H}), 7.16(\mathrm{t}, J=7.48 \mathrm{~Hz}, 1 \mathrm{H}), 7.04(\mathrm{t}$, $J=9.64 \mathrm{~Hz}, 1 \mathrm{H}), 6.97(\mathrm{~s}, 1 \mathrm{H}), 6.91(\mathrm{~s}, 1 \mathrm{H}), 5.16(\mathrm{~s}, 1 \mathrm{H})$, $2.22(\mathrm{~s}, 1 \mathrm{H}), 1.85(\mathrm{~s}, 1 \mathrm{H}), 1.62(\mathrm{~d}, J=3.96 \mathrm{~Hz}, 1 \mathrm{H}), 1.43$ $(\mathrm{d}, J=12.68 \mathrm{~Hz}, 2 \mathrm{H}), 1.38 \sim 1.33(\mathrm{~m}, 2 \mathrm{H}), 1.29 \sim 1.22(\mathrm{~m}$, 2H), $1.16(\mathrm{~s}, 6 \mathrm{H}), 1.10 \sim 1.04(\mathrm{~m}, 1 \mathrm{H}), 0.93(\mathrm{~s}, 3 \mathrm{H}), 0.86$ $(\mathrm{s}, 3 \mathrm{H}) ;{ }^{13} \mathrm{C}$ NMR $\left(100 \mathrm{MHz}, \mathrm{CDCl}_{3}\right) \delta: 173.5(\mathrm{~s}, 1 \mathrm{C}, \mathrm{C}=$ $\mathrm{S}), 160.1\left(J_{\mathrm{C}-\mathrm{F}}=246.03 \mathrm{~Hz}, 1 \mathrm{C}\right), 130.1\left(J_{\mathrm{C}-\mathrm{F}}=8.24 \mathrm{~Hz}\right.$, $1 C), 128.9\left(J_{\mathrm{C}-\mathrm{F}}=3.57 \mathrm{~Hz}, 1 \mathrm{C}\right), 128.5\left(J_{\mathrm{C}-\mathrm{F}}=12.97 \mathrm{~Hz}\right.$, $1 \mathrm{C}), 128.2,125.0\left(J_{\mathrm{C}-\mathrm{F}}=3.55 \mathrm{~Hz}, 1 \mathrm{C}\right), 115.8\left(J_{\mathrm{C}-\mathrm{F}}=21.57\right.$ $\mathrm{Hz}, 1 \mathrm{C}), 107.0,55.7,54.3,51.2,50.9,40.1,37.2,36.0$, 34.0, 32.8, 26.2, 24.6, 24.4, 24.0, 22.8; HRMS calcd for $\mathrm{C}_{23} \mathrm{H}_{30} \mathrm{FN}_{2} \mathrm{~S}[\mathrm{M}+\mathrm{H}]^{+}$385.2114, found 385.2115.

$(4 S, 6 a R, 9 R, 10 a R)-4-(2-M e t h y l p h e n y 1)-6,6,10,10$-tetramethyl-4,5,6,7,8,9,10,10a-octahydro-1H-6a,9-methanobenzo $[h]$ quinazoline-2(3H)-thione $(\mathbf{3 k})$ : White powder, yield $57.4 \%$, purity $99.2 \%$. m.p. $101.5 \sim 102.4{ }^{\circ} \mathrm{C} ;{ }^{1} \mathrm{H}$ NMR (400 MHz, $\left.\mathrm{CDCl}_{3}\right) \delta: 7.25(\mathrm{~s}, 1 \mathrm{H}), 7.21 \sim 7.19(\mathrm{~m}$, $2 \mathrm{H}), 7.14 \sim 7.12(\mathrm{~m}, 1 \mathrm{H}), 6.85(\mathrm{~s}, 1 \mathrm{H}), 6.71(\mathrm{~s}, 1 \mathrm{H}), 5.10$ $(\mathrm{s}, 1 \mathrm{H}), 2.40(\mathrm{~s}, 3 \mathrm{H}), 2.20(\mathrm{~s}, 1 \mathrm{H}), 1.85(\mathrm{~s}, 1 \mathrm{H}), 1.69(\mathrm{t}, J=$ $8.60 \mathrm{~Hz}, 1 \mathrm{H}), 1.51(\mathrm{dd}, J=3.84,3.80 \mathrm{~Hz}, 1 \mathrm{H}), 1.42(\mathrm{~d}, J=$ $10.8 \mathrm{~Hz}, 1 \mathrm{H}), 1.37 \sim 1.34(\mathrm{~m}, 1 \mathrm{H}), 1.27 \sim 1.24(\mathrm{~m}, 2 \mathrm{H})$, $1.23(\mathrm{~s}, 1 \mathrm{H}), 1.17(\mathrm{~s}, 3 \mathrm{H}), 1.16(\mathrm{~s}, 3 \mathrm{H}), 1.11(\mathrm{~d}, J=6.92$ $\mathrm{Hz}, 1 \mathrm{H}), 0.91(\mathrm{~s}, 3 \mathrm{H}), 0.82$ (s, 3H); ${ }^{13} \mathrm{C} \mathrm{NMR}(100 \mathrm{MHz}$,
$\left.\mathrm{CDCl}_{3}\right) \delta: 202.8(\mathrm{~s}, 1 \mathrm{C}, \mathrm{C}=\mathrm{S}), 138.0,136.1,135.9,135.3$, $130.3,128.9,128.4,125.5,63.3,55.9,48.4,44.9,40.7$, $37.8,32.0,30.7,28.5,25.8,25.7,24.8,24.0,20.1$; HRMS calcd for $\mathrm{C}_{24} \mathrm{H}_{33} \mathrm{~N}_{2} \mathrm{~S}[\mathrm{M}+\mathrm{H}]^{+} 381.2364$, found 381.2367.

(4S,6aR,9R,10aR)-4-(2-Methoxyphenyl)-6,6,10,10-tetramethyl-4,5,6,7,8,9,10,10a-octahydro-1H-6a,9-methanobenzo[ $h]$ quinazoline-2(3H)-thione (31): White powder, yield $54.1 \%$, purity $98.2 \%$. m.p. $106.8 \sim 107.3{ }^{\circ} \mathrm{C} ;{ }^{1} \mathrm{H}$ NMR $\left(400 \mathrm{MHz}, \mathrm{CDCl}_{3}\right) \delta: 7.30 \sim 7.28(\mathrm{~m}, 1 \mathrm{H}), 7.19(\mathrm{dd}$, $J=1.68,1.64 \mathrm{~Hz}, 1 \mathrm{H}), 6.96(\mathrm{t}, J=7.48 \mathrm{~Hz}, 1 \mathrm{H}), 6.89$ (s, $1 \mathrm{H}), 6.87(\mathrm{~s}, 1 \mathrm{H}), 6.67(\mathrm{~s}, 1 \mathrm{H}), 5.20(\mathrm{~s}, 1 \mathrm{H}), 3.84(\mathrm{~s}, 3 \mathrm{H})$, $2.25(\mathrm{~s}, 1 \mathrm{H}), 1.87(\mathrm{~s}, 1 \mathrm{H}), 1.81 \sim 1.72(\mathrm{~m}, 3 \mathrm{H}), 1.51 \sim 1.45$ $(\mathrm{m}, 2 \mathrm{H}), 1.35(\mathrm{~d}, J=8.2 \mathrm{~Hz}, 1 \mathrm{H}), 1.32 \sim 1.30(\mathrm{~m}, 2 \mathrm{H})$, $1.18(\mathrm{~s}, 3 \mathrm{H}), 1.17(\mathrm{~s}, 3 \mathrm{H}), 0.93(\mathrm{~s}, 3 \mathrm{H}), 0.87(\mathrm{~s}, 3 \mathrm{H}) ;{ }^{13} \mathrm{C}$ NMR (100 MHz, $\left.\mathrm{CDCl}_{3}\right) \delta: 173.5(\mathrm{~s}, 1 \mathrm{C}, \mathrm{C}=\mathrm{S}), 157.0$, $129.7,129.0,128.5,127.9,121.1,110.8,106.7,55.9,55.6$, $55.1,51.7,51.0,40.9,37.2,36.2,34.0,33.0,26.4,24.6$, 24.5, 24.0, 23.3; HRMS calcd for $\mathrm{C}_{24} \mathrm{H}_{33} \mathrm{~N}_{2} \mathrm{OS}[\mathrm{M}+\mathrm{H}]^{+}$ 397.2314, found 397.2317.

\subsection{Biological evaluation}

\subsubsection{Cell culture and treatment}

The tumor cells whose growth phase are logarithmic phase were digested with digestive trypsin. Then, appropriate amount of DMEM (Dulbecco's Modified Eagle Medium) serum was added in it, and counted using the hemocytometer. After that, the cell suspensions were diluted to $5 \times 10^{3} \sim 1 \times 10^{4}$ viable cells per well. $100 \mu \mathrm{L}$ cell suspensions were added to each well in a 96-well culture plate, incubated for $24 \mathrm{~h}$ in an incubator and made the cells adhere. Then, the tumor cells were incubated with different concentrations of the target compounds. Cell viability was evaluated by measuring the metabolism of 3-(4,5dimethyl-2-thiazolyl)-2,5-diphenyl- $2 \mathrm{H}$-tetrazolium bromide (MTT) after $72 \mathrm{~h}$. Briefly, the MTT reagent (1 $\mathrm{mg} / \mathrm{mL}$ ) was added into each well. $4 \mathrm{~h}$ later, the culture medium of each well was removed and $100 \mathrm{~mL}$ dimethyl sulfoxide (DMSO) was added. 15 min later, the absorbance was measured at $570 \mathrm{~nm}$ by a plate reader. $\mathrm{IC}_{50}$ values were determined by Excel from Nanjing Forestry University. The results were summarized in Table 2 .

\subsubsection{Cell apoptosis and cell cycle}

The MDA-MB-231 cells were digested and counted to make a cell suspension of $1 \times 10^{5}$ cells $/ \mathrm{mL}$. Then seeded them into a 6-well plate $(1 \mathrm{~mL} / \mathrm{well})$ and incubated in incubator for $24 \mathrm{~h}$. After that, the tumor cells were incubated with different concentrations of compound $\mathbf{3 j}$. Finally, by putting the 6-well plate to incubate in the incubator for 48 $\mathrm{h}$, the morphological changes in each group were observed under a microscope, and cell apoptosis and cell cycle were monitored by flow cytometry.

Supporting Information ${ }^{1} \mathrm{H} \quad \mathrm{NMR},{ }^{13} \mathrm{C} \quad \mathrm{NMR}$ and HRMS spectra of the target compounds $\mathbf{3 a} \sim \mathbf{3 1}$. Supplementary data can be found at http://sioc-journal.cn/ 


\section{References}

[1] Ferlay, J.; Soerjomataram, I.; Dikshit, R. Int. J. Cancer 2015, 136, E359.

[2] Stewart, B.; Wild, C. P. World Health Organization 2017.

[3] Jain, K. S.; Chitre, T. S.; Miniyar, P. B. Curr. Sci. 2006, 90, 793.

[4] Maga, G.; Radi, M.; Gerard, M.A.; Botta, M. Viruses 2010, $2,880$.

[5] Deshmukh, M. B.; Salunkhe, S. M.; Patil, D.R.; Anbhule, P. V. Eur. J. Med. Chem. 2009, 44, 2651.

[6] Masoud, M. S.; Ibrahim, A. A.; Khalil, A. E.; Marghany, E. Spectrochim. Acta, Part A 2007, 67, 662.

[7] Fathalla, O. A.; Awad, S. M.; Mohamed, M. S. Arch. Pharm. Res. 2005, 28, 1205.

[8] Odani, A.; Kozlowski, H.; Swiatek Kozlowska, J.; Brasun, J.; Operschall, B. P.; Sigel, H. J. Inorg. Biochem. 2007, 101, 727.

[9] Moustafa, H.; Shibl, M. F.; Hilal, R. Phosphorus Sulfur 2005, 180, 459.

[10] Palumbo, A.; D'Ischia, M. Biochem. Bioph. Res. Commun. 2001, 282, 793 .

[11] Smith, J.; Liras, J. L.; Schneider, S. E.; Anslyn, E. V. J. Org. Chem. 1996, 61, 8811.

[12] Yan, Z. K.; Song, B. A.; Yang, X.; Hu, D. Y.; Yang, S.; Jin, L. H.; Chen, G. M. Agrochemicals 2008, 47, 706.

[13] Fathalla, O. A.; Zaghary, W. A.; Radwan, H. H.; Awad, S. M.; Mohamed, M. S. Arch. Pharm. Res. 2002, 25, 258.
[14] Okabe, N.; Fujiwara, T.; Yamagata, Y.; Tomita, K. I. Chem. Soc. Jpn. 1983, 56, 1543.

[15] Hu, Y. S.; Li, M.; Zhong, G. X. Zhejiang Chem. 2010, 41, 8.

[16] Padro, T.; Vandenhoogen, C. M.; Emeis, J. J. Blood. Coagullation Fibrinolysis 1993, 4, 797.

[17] Peebles, E. D.; Miller, E. H.; Boyle, C. R.; Brake, J. D.; Latour, M. A.; Thaxton, J. P. Poult. Sci. 1997, 76, 236.

[18] RamdasNayak, U.; Sukh, D. Tetrahedron 1960, 8, 42.

[19] Prahlad, J. R.; Nayak, U. R.; Dev, S. Tetrahedron 1970, 26, 663.

[20] Sell, D. H.; Pybus, C.; Sell, C. S. Cambridge 1999, 81, 24.

[21] Panten, J.; Bertram, H. J.; Surburg, H. Chem. Biodiversity 2004, 1, 1936.

[22] Jain, A. K.; Vaidya, A.; Ravichandran, V. Bioorg. Med. Chem. 2012, $20,3378$.

[23] Khan, S. A.; Yusuf, M. Eur. J. Med. Chem. 2009, 44, 2597.

[24] Verma, A.; Saraf, S. K. Eur. J. Med. Chem. 2008, 43, 897.

[25] Vicini, P.; Geronikaki, A.; Incerti, M. Bioorg. Med. Chem. 2008, 16, 3714.

[26] Rui, J.; Yang, J. L.; Huang, J. F. Chin. J. Org. Chem. 2016, 36, 2183 (in Chinese).

(莴坚, 杨金来, 黄建峰, 有机化学, 2016, 36, 2183.)

[27] Wang, Z.; Yang, J.; Liu, P. Tetrahedron 2017, 73, 5912.

[28] Wang, Z. L; Yang, J. L; Yang, Y. Q. RSC Adv. 2017, 7, 33263.

[29] Rui, J.; Cai, T.; Yang, J. L. J. Nanjing For. Univ. 2016.

[30] Wang, Y. Y.; Gu, W.; Shan, Y. Bioorg. Med. Chem. Lett. 2017, 27, 2360 .

(Lu, Y. J.) 